\title{
Morfología de la profesión académica en la Universidad Nacional de San Juan
}

\author{
Algañaraz Soria, Víctor Hugo*
}

\section{Resumen}

El artículo presenta los resultados de un estudio de caso sobre el devenir y configuración reciente de la «profesión académica» en una institución que, por sus características histórico-estructurales, puede considerarse como periférica en el sistema universitario argentino: la Universidad Nacional de San Juan. Se abordan, específicamente, dos dimensiones analíticas: su estructura académica (esto es, las «posiciones» del cuerpo docente según cargos, categorías y dedicaciones, y su relación con la función de investigación) y el régimen de Carrera Docente vigente, dando cuenta de su devenir, particularidades y mecanismos de evaluación previstos para el ingreso/permanencia/promoción docentes, a partir de visibilizar diversas «tomas de posición» del profesorado universitario. La metodología incluye un acceso documental (examinando estadísticas públicas y marcos normativos específicos) y otro etnográfico (recuperando diversas voces docentes $y$, particularmente, las opiniones de referentes sindicales). Los hallazgos principales indican que, aunque la universidad asume una estructura académica segmentada, manifestándose una alta concentración de cargos en su base, el nuevo régimen de Carrera Docente ha promovido mayores márgenes de estabilidad y crecimiento profesional.

Palabras clave: profesión académica; docentes universitarios; estructura académica; Carrera Docente; Universidad Nacional de San Juan

Este artículo procede de una línea de investigación acreditada/financiada mediante los proyectos: «Ciencia y docencia en la Universidad Nacional de San Juan (1994-2017). Impactos del Programa Incentivos y Carrera de Investigador del CONICET en la estructura científica institucional» (PICT-ANPCYT 2018-2019, Res. N. : 310-18) e «Impacto de la política científica nacional en la UNSJ» (CICITCA-UNSJ 2018-2019, Res. N. ${ }^{\circ}$ 021/28-CS), dirigidos por el autor en el Instituto de Investigaciones Socioeconómicas (Facultad de Ciencias Sociales, UNSJ). Recibido el 11/06/2020 y aceptado el 29/09/2020. Publicado el 02/05/2021. Dol: https://doi.org/10.33255/3262/792

Autoría: *Universidad Nacional de San Juan (Argentina) - Conicet.

Contacto: victor.algz@gmail.com 


\section{Morphology of the academic profession at the National University of San Juan} Abstract

The article presents the results of a case study on the recent become of the «academic profession» in an institution that, due to its historical-structural characteristics, can be considered as peripheral in the Argentine university system: The National University of San Juan. Two analytical dimensions are specifically addressed: its academic structure (that is, the «positions» of the teaching body according to post, categories and dedications and its relation to the research function) and the current teaching career regime, accounting for its depvelopment, particularities and evaluation mechanisms foreseen for the entry / permanence / promotion of teachers, from making visible the «positions taken» by university teachers. The methodology includes a documentary access (examining public statistics and specific regulatory frameworks) and an ethnographic one (recovering diverse teachers voices and, in particular, the opinions of syndical referents). The main findings indicate that, although the University assumes a segmented academic structure, manifesting a high concentration of posts at its base, the new teaching career regime has promoted greater margins of stability and professional growth.

Keywords: academic profession; university teachers; academic structure; Teaching Career; National University of San Juan

\section{Morfologia da profissão acadêmica na Universidade Nacional de San Juan Resumo}

O artigo apresenta os resultados de um estudo de caso sobre o desenvolvimento e configuração recente da «profissão acadêmica» em uma instituição que, por suas características histórico-estruturais, pode ser considerada periférica no sistema universitário argentino: a Universidade Nacional de San Juan. São abordadas, especificamente, duas dimensões analíticas: a sua estrutura acadêmica (ou seja, as «posições» do corpo docente segundo cargos, categorias e dedicações e sua relação com a função de pesquisa) e o atual regime de carreira docente, dando conta de seu devir, das particularidades e dos mecanismos de avaliação previstos para o ingresso/permanência/promoção dos docentes, a partir de visibilizar diversas «tomadas de posição» dos professores universitários. A metodologia inclui um acesso documental (examinando estatísticas públicas e marcos regulatórios específicos) e outro etnográfico (recuperando diversas vozes docentes e, em particular, as opiniões de dirigentes sindicais). Os principais resultados indicam que, embora a Universidade assume uma estrutura acadêmica segmentada, apresentando elevada concentração de cargos na sua base, o novo regime de carreira docente tem promovido maiores margens de estabilidade e crescimento profissional.

Palavras-chave: profissão acadêmica; professores universitários; estrutura acadêmica; carreira docente; Universidade Nacional de San Juan 


\section{Introducción}

La llamada «profesión académica» viene consolidándose como campo específico de estudios desde hace mucho tiempo, pero en las últimas décadas ha cobrado un renovado y creciente impulso nacional e internacional. Procurando contribuir en esta dirección, el presente artículo muestra los resultados de una investigación sobre su configuración en la Universidad Nacional de San Juan (UNSJ).

Gran parte de los trabajos abocados al estudio de la temática en el país poseen un fecundo anclaje en los escritos de Pierre Bourdieu. Los mismos han aportado categorías epistémicas centrales con una gran potencialidad explicativa para dar cuenta de las tendencias macroestructurales del campo científico-universitario nacional y reconocer el posicionamiento histórico-institucional de sus principales organismos y agentes dinamizadores. Si bien la perspectiva epistemológica general de este estudio se sostiene también sobre la sociología reflexiva de Bourdieu (1995), esta ha funcionado más bien como una caja de herramientas proveyendo ciertas categorías analíticas específicas que fueron aplicadas (y reperfiladas) en el abordaje empírico de la UNSJ. En este sentido, han sido recuperados también aportes de dos enfoques analíticos que suelen entrecruzarse en el abordaje de este tipo de trabajos: el campo de estudios de la educación superior (De La Fare, Rovelli y Lenz, 2013; Marquina, 2013; García de Fanelli, 2009, entre otros) y el campo de estudios de la ciencia, la tecnología y la sociedad (Vessuri y Canino, 2007; Kreimer y Thomas, 2004, etc.), que han permitido dotar de historia a la institución y de protagonismo a sus integrantes.

El propio Bourdieu (2009) ha reconocido que el campo científico es un sistema de fuerzas estructuradas y estructurantes, donde las diversas instituciones y agentes que lo conforman luchan por situarse en posiciones hegemónicas y monopolizar el capital científico circulante, pero aunque comparten una misma illusio conservan importantes márgenes de autonomía. Asentados en esta perspectiva, autores como Emirbayer y Johnson (2008) propugnan distanciarse de la óptica macroinstitucional del campo muy extendida en los estudios bourdiesianos y precisar el foco de análisis más bien en las estructuras e interacciones de las instituciones específicas que lo conforman, pues ellas le confieren su especificidad. En efecto, si bien cada institución se halla situada dentro de las fronteras de un campo nacional determinado y hereda sus reglas generales de juego, revisten ciertas particularidades, dinámicas histórico-sociales e intereses propios. De allí que el presente trabajo focalice en la UNSJ como caso de estudio instrumental, pero situando la 
cuestión en el marco del proceso de expansión heterogénea experimentado por el campo científico-universitario argentino en años recientes. Pues, tal como ha señalado Karin Knorr Cetina (1995: 163) en una de sus obras clásicas, "cuando aprendemos de los estudios de laboratorio sobre el carácter "situado" del conocimiento, ello puede ser aplicado a cuestiones más amplias sobre la localización de la experiencia social en sitios múltiples y variados».

En el plano metodológico, Marradi, Archenti y Piovani (2007) han señalado que el estudio de caso es una estrategia de investigación relevante y fructífera para el abordaje de instituciones específicas. A partir de seleccionar ciertas propiedades de análisis (variables y/o dimensiones), permite alcanzar mayor profundidad analítica y ahondar en la complejidad del fenómeno o los fenómenos abordados. En cuanto a la UNSJ, reviste interés como caso de estudio, no solo porque se trata de una institución menos explorada por la literatura especializada sino porque sus características estructurales, ubicación geográfica y antigüedad permiten considerarla como una universidad periférica dentro de un centro académico periférico como es Argentina en el escenario mundial.

En cuanto al desarrollo del trabajo, se ha adoptado un diseño de investigación interactivo (Maxwell, 1996) que brinda una estructura interconectada y flexible de las distintas fases de la pesquisa. En sintonía, se han empleado articuladamente dos principales accesos metodológicos: uno documental y otro etnográfico. El primero está signado por información proveniente de un cuerpo de fuentes secundarias, principalmente documentos públicos e institucionales (como leyes, decretos, informes de evaluación institucional, el Estatuto Universitario de la UNSJ y el Reglamento de Carrera Docente vigente), así como bases de datos estadísticas: anuarios de la Secretaría de Políticas Universitarias (SPU) y bases con información institucional sobre el cuerpo de docentes de la universidad, de docentes-investigadores/as del Programa Incentivos y aquellos que cumplen labores como becarios/as e investigadores/ as del Consejo Nacional de Investigaciones Científicas y Técnicas (CONICET). En cuanto al segundo acceso, mediante entrevistas en profundidad de carácter semiestructuradas se han recuperado diversos testimonios de informantes claves de la institución seleccionados de acuerdo con un criterio teórico: se trata de docentes-investigadores/as, entre ellos funcionarios y referentes sindicales. Dado que el establecimiento del régimen de Carrera Docente en la UNSJ ha sido uno de los reclamos históricos de la comunidad en general y del sindicalismo docente en particular, ha sido fundamental para este trabajo rescatar las opiniones expresadas al respecto por los secretarios generales de los dos gremios con representatividad en la institución: el «Sindicato de 
Trabajadores Docentes de la UNSJ» (SIDUNSJ) y la «Asociación de Docentes, Investigadores y Creadores de la UNSJ» (ADICUS).

El artículo procura, en suma, precisar las singularidades de la profesión académica en la universidad pública de San Juan, a partir de examinar dos dimensiones analíticas específicas: las «posiciones» ocupadas por sus docentes en la estructura académica y las diversas «tomas de posición» de varios de ellos/as respecto al régimen de Carrera Docente recientemente aprobado. El argumento central que guía la indagación sostiene que si bien la estructura ocupacional de la UNSJ, que deriva de su historia y devenir social y político, ha asumido una configuración segmentada -con una alta concentración de cargos menores en su base y una cúspide con poder simbólico más angosta-, afectando las condiciones de carrera del colectivo docente, la puesta en juego del nuevo marco normativo ha generado un escenario más propicio y de mayor certidumbre para lograr estabilidad laboral y movilidad de carrera.

El escrito se organiza en tres apartados principales. El primero presenta un recorrido histórico-conceptual sobre la noción de profesión académica, situando su devenir en el marco del heterogéneo campo científico-universitario nacional. El segundo focaliza en la estructura académica de la UNSJ, describiendo las «posiciones» detentadas por sus docentes (según tipos de cargos, categorías y dedicaciones) y la incidencia del Programa Incentivos y carrera científica del CONICET. El tercero examina el Reglamento de Carrera Docente vigente, visibilizando (mediante testimonios de académicos) las diversas «tomas de posición» en la institución sobre su puesta en marcha y los mecanismos previstos para el ingreso, permanencia y promoción docente.

\section{Un recorrido histórico-conceptual sobre el devenir de la «profesión académica» y su configuración en el campo científico-universitario argentino}

El interés por el estudio del «trabajo académico» como profesión, la conformación de su estructura ocupacional, las vías de ingreso y promoción profesional, la articulación de la tradicional labor docente con otras funciones de la universidad (como investigación, extensión, transferencia y gestión), los criterios de evaluación, la calidad de los programas e instituciones universitarias mismas, así como el impacto de la cultura académica mundial, viene creciendo a nivel nacional e internacional en las últimas décadas dentro de lo que diversos autores han llamado «profesión académica». De hecho, la conceptualización sobre el tema es de larga data y de carácter polisémico y la literatura disponible al respecto es bastante profusa 1 . 
El uso más habitual del término «profesión académica» ha devenido del ámbito angloamericano para referirse, precisamente, al trabajo realizado por académicos/as, entendiendo genéricamente las actividades de enseñanza y también de investigación que realizan las y los profesores universitarios. Aunque, como sabemos, actualmente sus planes de trabajo se distribuyen entre las diferentes funciones misionales de la universidad excediendo el binomio docencia-investigación. Algunos estudios han reconocido en la «profesión académica» la matriz fundante del resto de las profesiones, una suerte de «profesión de las profesiones» (García, 2017; Marquina, 2013; García de Fanelli, 2009). No obstante, según los diversos contextos nacionales, su operacionalización analítica ha sido diferencial, dada su acentuada heterogeneidad en términos disciplinares, del tipo de gestión de la universidad (pública o privada), de la organización intrainstitucional de la función docente y roles complementarios o de las jerarquías establecidas dentro cada Carrera Académica.

Al respecto, algunos estudios clásicos (como los trabajos de Altbach y Finkelstein, 1997, o el de Burton Clark, 1987) han reconocido los diversos sentidos que adquirió el término en los ámbitos académicos de algunos de los llamados países centrales:

- en Alemania, por ejemplo, remite al vínculo entre la profesionalización de la ciencia y el trabajo académico, devenido tras la transición del emblemático formato de universidad de investigación hacia una institución de masas;

- en Francia refiere a la competitividad y diversidad que han signado las burocracias profesionales de su sistema científico-universitario, especialmente luego de las protestas estudiantiles de los años 60;

- en Inglaterra refleja las idiosincrasias propias de las diversas culturas disciplinares e institucionales donde se ejercen las respectivas profesiones; y - en Estados Unidos, luego de la Segunda Guerra Mundial cuando las universidades colaboraron con el gobierno, ha prevalecido la noción de trabajadores con diferentes habilidades formados en espacios disciplinares especializados.

Otros estudios (Stromquist, 2009; Albatch, 2004; Farnham, 1999 y Blau, 1973) han focalizado en los efectos de los procesos de masificación, diversificación e internacionalización en el ejercicio de la profesión académica desde una perspectiva comparada, señalando el impacto que ha generado la progresiva segmentación de la educación superior (intra e inter países) en las trayectorias de las y los profesores universitarios. Entre los principales corolarios identificados, han señalado una mayor afluencia y relativa concentración de los mejores 
docentes en los centros de elite de cada país o su movilidad académica hacia países económicamente más avanzados, que se supone cuentan con mayor financiamiento para los procesos de formación e investigación y suelen otorgar mayores beneficios laborales y mejores ingresos.

En este marco, ha sido determinante el rol de las publicaciones indexadas, rankings universitarios e indicadores bibliométricos, tras acrecentarse su peso en los procesos de evaluación y financiamiento de las universidades y de las/ los mismos docentes. Por el lado de las instituciones, la creciente utilización de estos parámetros considerados más «universales» y «objetivos» devino en su jerarquización/subordinación conforme a sus performances en dichas bases de datos, otorgando primacía a la llamada corriente central del conocimiento por sobre los entornos considerados «periféricos», incrementándose los flujos de estudiantes y profesores con una lógica Sur-Norte. Por el lado de los académicos/as, estos criterios de «calidad» y «excelencia» (Vessuri, Guedón y Cetto, 2014) se han impuesto cada vez más en sus instancias de evaluación, desplazando relativamente la antigua modalidad de designación/promoción docente anclada en redes personales y en la autoridad de decanos o directores de carrera.

No obstante, diversos autores (Beigel et al., 2018; Vasen y Lujano, 2017, y Naidorf y Perrotta, 2016) han discutido la idea de una mera dependencia académica y coinciden en señalar que no hay un formato unidireccional de imposición de estándares científicos y académicos originados en los campos mainstream ya que, de hecho, la periferialidad científica misma se ha diversificado, sosteniéndose cada vez más por sus propias capacidades locales. En efecto, en las últimas décadas se ha ido complejizando/diversificando la profesión académica en la «periferia», trascendiendo la mera subordinación a las estrategias de consagración impuestas desde los centros de excelencia. En América Latina, por ejemplo, los campos académicos han asumido una configuración heterogénea y segmentada, identificándose diversos formatos de producción y circulación del conocimiento: hay docentes y científicos/as más integrados a los estilos mainstream, otros que participan en circuitos regionales alternativos (contribuyendo a aumentar la investigación colaborativa y los flujos académicos Sur-Sur) y algunos más que permanecen vinculados a sus agendas endógenas.

Dada, entonces, la heterogeneidad estructural de las academias latinoamericanas, el devenir y conceptualización de la «profesión académica» ha asumido un carácter particular en la región, más ligado al proceso de segmentación institucional/disciplinar y su tradicional estructura profesionalista. Ciertos autores (Marquina, 2013; De la Fare, Rovelli y Lenz, 2013; García de 
Fanelli, 2009; Schwartzman, 1993) han identificado distintos tipos de ejercicio de la profesión, desde mediados de siglo XX en adelante:

a. el clásico rol del profesor/a de tiempo parcial o con baja dedicación horaria a la enseñanza universitaria (estilo catedrático) para el que, si bien obtiene prestigio y poder de la docencia, esta no constituye su ocupación principal y se dedica más a la práctica liberal de su profesión (como médicos, contadores u abogados, por ejemplo);

b. el profesor/a dedicado a la enseñanza a tiempo completo en la universidad (con un perfil más académico), que obtiene de allí su fuente principal de ingresos, devenido esencialmente de las políticas de modernización y ampliación del acceso a la educación superior de los años 50-60; y c. el/la docente que también realiza tareas científicas (estilo docente-investigador/a), compartiendo la disponibilidad de su tiempo entre la transmisión y la producción de conocimientos, proviniendo sus ingresos de la misma universidad o en complemento con algún centro científico-tecnológico. Este perfil se consolidó tras las reformas de los Sistemas de Educación Superior de los años 80-90 que, vía políticas de evaluación y financiamiento, impactaron en la labor docente.

A la fecha, el trabajo académico se ha diversificado aún más, distinguiéndose también labores extensionistas, transferencistas y de gestión en las diversas estructuras universitarias. Pero, como puede apreciarse, los procesos de construcción de las carreras académicas y profesionalización de la docencia universitaria se hallan articulados estrechamente con la actividad científica en la región. Ambas funciones de la profesión académica, la de enseñanza y la de investigación, constituyen una compleja relación-tensión que ha hecho mella no solo a nivel del desempeño profesional de cada docente sino también, y principalmente, a nivel institucional en cada contexto nacional.

Esta tensión estructural entre investigación y docencia subyace, específicamente, en la configuración histórico-institucional del «campo científico-universitario» argentino. Al respecto, Beigel y Bekerman (2019: 269) han señalado que entre los ámbitos «universitario» y «científico-tecnológico» del país han mediado históricamente múltiples reglamentaciones, clasificaciones y escalafones que obstaculizaron sus vasos comunicantes. No obstante, más que un campo desarticulado se trata de un espacio dinámico, atravesado por múltiples condiciones de integralidad y heterogeneidad. Entre sus rasgos distintivos, se destaca una clara orientación a la internacionalización, pero que convive con permanentes acciones nacionalizantes, y que tradicionalmente ha sido permeado por asimetrías regionales, institucionales y disciplinares, 
siendo signado precisamente por un divorcio histórico entre investigación y docencia.

Un hito importante en la disociación entre ambas actividades tuvo lugar tras la política científico-autoritaria impartida por la última dictadura militar (1976-1983), que fortaleció los espacios extrauniversitarios en el país. Especialmente el CONICET consolidó su perfil como principal organismo nacional dedicado a la producción de conocimientos y formación de vocaciones científicas, a partir de crear numerosos institutos de investigación descentralizados en varias provincias. En simultaneo, las actividades de investigación que por entonces se desarrollaban en las universidades públicas fueron discontinuadas, sus laboratorios e institutos clausurados y muchos de sus docentes encarcelados o desaparecidos (Algañaraz y Bekerman, 2014).

Tras el retorno democrático se desplegaron varios intentos por restablecer el vínculo entre las universidades y el CONICET. Pero, aunque la matrícula universitaria experimentó una fuerte expansión y las mismas instituciones se multiplicaron, el alcance de las políticas gubernamentales fue disímil según universidades y áreas de conocimiento, lo que en muchas de ellas cristalizó en un débil financiamiento a sus actividades o programas de investigación, fortaleciéndose, en suma, la bisagra institucional respecto al mencionado Consejo Nacional de Investigaciones.

A partir de los años 90, como parte de políticas universitarias activas asumidas como mecanismos indirectos de intervención estatal, la evaluación logró implantarse como herramienta predilecta para el mejoramiento de la calidad en la profesión académica. En este marco, bajo el ámbito de la SPU se implementó el «Programa de Incentivos a Docentes Investigadores» (PROINCE), que condicionó fuertemente las prácticas académicas de los profesores/as y generó cambios profundos en las culturas universitarias (Sarthou, 2014; Prego y Prati, 2006). En lo formal, el PROINCE estaba destinado a promover la investigación en las universidades y fomentar una mayor dedicación de los y las docentes a las actividades científicas. En pos de ello, se dispuso adicionar al salario un «incentivo» económico para quienes realizaran actividades integradas de investigación y docencia. Se fortaleció así la figura de «docenteinvestigadores» dentro de la profesión académica, esto es: el subgrupo de profesores/as universitarios que, habiendo sido evaluados por pares, contaron con una «categoría de investigación específica» prestablecida según un rango jerárquico (actualmente I, II, III, IV y V), percibiendo por tanto un plus salarial acorde a la categoría obtenida?

Transcurridas casi tres décadas desde su implementación, el PROINCE ha alcanzado un éxito relativo. Por un lado, ha coadyuvado a expandir la 
práctica investigativa más sistemática por fuera del principal organismo científico del país (el CONICET), al tiempo que ha desplazado la investigación universitaria de tipo vocacional y más vinculada a las actividades de cátedra, en favor de un nuevo quehacer científico de los/las docentes más regulado institucionalmente. Pero, por otro lado, si bien legitimó la figura del docente-investigador/a que debe acreditar enseñanza e investigación (participando en proyectos, asistiendo a congresos y publicando, por ejemplo), este convive cotidianamente en el recinto universitario con el/la docente tradicional que está abocado solo a las actividades de enseñanza. Además, los/las docentes de las máximas categorías del Programa ( y II) han ido conformando un nuevo segmento académico que se distingue de sus pares no tanto por las retribuciones económicas alcanzadas, sino fundamentalmente porque gozan de mayor prestigio y cuotas de poder institucional (concentran la dirección de proyectos de investigación acreditados y por tanto de recursos materiales para la investigación, a la vez que monopolizan la dirección de becarios/as y tesistas de grado y posgrado, es decir, de recursos humanos).

Luego de la crisis estructural del 2001-2002, por efecto de una serie de políticas gubernamentales (fundamentalmente la inyección de recursos públicos), el campo científico-universitario nacional experimentó una fuerte expansión e intentos de articulación entre las esferas de investigación y docencia. Tuvo lugar, entonces, una triplicación de becarios/as e investigadores/as del CONICET y se crearon varios institutos dependientes de dicho organismo (algunos asentados en las universidades públicas), se fortalecieron las carreras de doctorado, se repatriaron cientos de científicos/as, muchos de los cuales se incorporaron a la docencia universitaria al igual que varios de los becarios/as e investigadores/as jóvenes del CONICET (Unzué y Emiliozzi, 2017).

Entre 2003 y 2015, tanto las universidades públicas como el Consejo Nacional de Investigaciones desplegaron importantes esfuerzos para modificar su histórico distanciamiento, promoviendo instancias de investigación colaborativas, proyectos y becas cofinanciadas, así como actividades de vinculación/ transferencia. Se puso de manifiesto que no se trata de espacios institucionales compartimentados sino vinculados, aunque diferencialmente. Por ambos sitios circulan cotidianamente docentes, investigadores/as y becarios/as que son permanentemente evaluados en su productividad y labores; aunque el proceso de construcción de sus carreras académicas es muy diverso. Entre los varios perfiles circulantes, pueden identificarse:

Por una parte, investigadores altamente internacionalizados, construyendo sus carreras en el CONICET, pero participando de la vida universitaria en distintos 
niveles, desde un cargo docente simple hasta dirigiendo institutos de investigación y carreras de posgrado. Por otra parte, investigadores con un habitus local que han alcanzado importantes niveles de reconocimiento institucional en las universidades nacionales, categorizados en el PROINCE, ajenos a la carrera del CONICET (Beigel y Bekerman, 2019: 96).

En suma, como resultado de los procesos histórico-estructurales mencionados, el campo científico-universitario nacional se ha configurado como un espacio predominantemente público y heterogéneo. En cuanto a su carácter público, vale mencionar que el CONICET y las universidades de gestión estatal concentran aproximadamente el $80 \%$ del personal dedicado a las actividades científicas y de educación superior de todo el país y son responsables también de las cuotas más importantes del gasto nacional invertido en la materia (MINCyT, 2020). En cuanto a su heterogeneidad estructural, no se trata solo de un tipo de "heterogeneidad horizontal o inter-institucional», devenida principalmente de la distribución desigual de recursos entre el CONICET y las universidades o entre provincias e instituciones, sino también de una «heterogeneidad vertical o intra-institucional». En las universidades, por ejemplo, se observan estructuras segmentadas, en función de la cantidad y los tipos de carreras impartidas, la inclusión o no de posgrados en su oferta académica, el grado de formación académica alcanzado por sus profesores/as, el número de docentes disponibles y los tipos de cargos que detentan, la cantidad de centros/laboratorios/institutos de investigación con que cuentan y las áreas disciplinares correspondientes así como las características de la matrícula estudiantil (cantidad, origen social e institución media de procedencia, etc.), y por supuesto las partidas presupuestarias asignadas y recursos propios que poseen.

La profesión académica no reviste, entonces, un significado unívoco ni ha devenido en una modalidad específica de construcción de Carrera Docente. En tanto proceso de consecución, atribución y distribución de capitales específicos (cultural y simbólico, principalmente) es resultado del impacto de la cultura académica internacional, las reglas del propio campo nacional, las políticas públicas gubernamentales, las regulaciones autónomas de cada universidad y, por supuesto, la trayectoria de cada docente. De allí que en las secciones subsiguientes de este trabajo, se acercará la lupa especialmente a la UNSJ, constituida en el caso de estudio instrumental. 


\section{Estructura de la profesión académica en la UNSJ: segmentación del cuerpo docente y contrapesos de la función de investigación}

El devenir de la UNSJ contrasta con algunas universidades más tradicionales del país (como la de Buenos Aires, Córdoba o La Plata), que por su tamaño, antigüedad, capacidades institucionales y localización en zonas económicamente más favorables fueron cosechando a lo largo de su trayectoria mayores cuotas de prestigio académico. La UNSJ se inscribe en una provincia relativamente pequeña que, según proyecciones del último censo poblacional, cuenta a la fecha con un total de 781.217 habitantes y cuya economía estuvo signada históricamente por el monocultivo y el empleo estatal y recién en las últimas décadas logró diversificar su aparato productivo vinculando actividades agrícolas, industriales, comerciales y mineras. Ello conllevó a que dicha universidad se constituyera en una institución académica de tipo periférica, distanciada del conglomerado de las grandes universidades argentinas ubicadas mayoritariamente en las regiones metropolitana y bonaerense del país.

La UNS fue creada el 10 de mayo de 1973 en el marco del llamado «Plan Taquini», que procuró descentralizar/despolitizar el sistema universitario nacional creando nuevas instituciones en el «interior». Su institucionalización fue promovida, además, por numerosas iniciativas de distintos colectivos sociales de la provincia que buscaban consolidar el desarrollo científico y profesional local, evitando que las y los estudiantes (futuros profesionales) debieran desplazarse a otros lugares. Fue el entonces presidente de facto general Alejandro A. Lanusse, mediante la ley . $^{\circ} 20.367$, quien promulgó la creación de esta universidad pública de gestión nacional en San Juan, potenciando así la región académica centro-oeste del país. Para su funcionamiento le fueron transferidos una serie de organismos y capacidades institucionales preexistentes: principalmente la Facultad de Ingeniería que entonces dependía de la Universidad Nacional de Cuyo (UNCuyo) en Mendoza y la antigua Universidad Provincial "Domingo F. Sarmiento», obteniendo de ellas diversos bienes muebles e inmuebles y sosteniéndose sobre su imagen social y capital cultural acumulado.

En un trabajo reciente (Algañaraz, 2019), hemos analizado las principales etapas de desarrollo de la UNSJ: génesis y reestructuración autoritaria (19731983); reinstitucionalización democrática (1983-1989); jerarquización estructural (1990-2002) y desarrollo heterogéneo (2003-2018). Aquí solo diremos que la institución fue reestructurada/diezmada en todas sus actividades durante la última dictadura y que recién en 1989, tras el retorno democrático, instituyó su propio estatuto universitario, adquiriendo mayores cuotas de autonomía y 
autarquía institucional. Recién entonces reguló los diferentes tipos de cargos, categorías y dedicaciones docentes, estableciendo los concursos de antecedentes y oposición como vías de ingreso y promoción. Estos factores histórico-estructurales devinieron en la configuración de una estructura académica segmentada y condicionaron el espacio de posibilidades de desempeño y movilidad del profesorado universitario. De hecho, fue con posterioridad a la crisis del 2001-2002 cuando la institución se planteó la necesidad de contar con un marco normativo específico de la profesión académica, pero fue recién en 2017 cuando el Consejo Superior aprobó el «Reglamento de Carrera Docente».

De acuerdo con los informes institucionales disponibles -de autoevaluación (UNSJ, 2011a) y evaluación externa (CONEAU, 2015)-, la UNS está conformada a la fecha por cinco facultades: de Ingeniería; de Ciencias Exactas, Físicas y Naturales; de Filosofía, Humanidades y Artes; de Arquitectura, Urbanismo y Diseño, y de Ciencias Sociales. La integran, además, una Escuela Universitaria en Ciencias de la Salud, tres colegios preuniversitarios (Industrial; de Comercio y Central Universitario) y varias delegaciones establecidas en departamentos alejados de la Ciudad de San Juan (como Jáchal, Iglesia y Valle Fértil) donde también se realizan diversas actividades académicas vía convenios entablados con el gobierno provincial y municipios.

En cuanto a su oferta académica, se cuentan a la fecha 69 carreras de grado y 53 de posgrado. En torno a ellas, la población estudiantil se distribuye del siguiente modo (SPU, 2017a): el grado está integrado por 27.338 estudiantes matriculados (entre nuevos inscriptos y reinscriptos), siendo el $57 \%$ mujeres y el $43 \%$ varones, registrándose en total 1.434 egresados. Respecto a los posgrados, el número de estudiantes asciende a 1.518 correspondiendo 347 a doctorados, 642 a maestrías y 529 a especializaciones 3 . Respecto a ello, el último informe de evaluación externa de la CONEAU (2015: 13) ha revelado que:

Por la oferta académica de pregrado, grado y posgrado que posee, la UNSJ recibe estudiantes no solamente de toda la provincia sino también de provincias vecinas como La Rioja, Mendoza y San Luis, y otras inclusive más alejadas, como por ejemplo Salta y Jujuy. Para el cursado de carreras de posgrado la UNSJ es receptora de estudiantes de diversos países de Latinoamérica.

Ahora bien, un punto de partida relevante en el análisis de la profesión académica lo constituye indagar la morfología general de cargos en la universidad, en la medida en que su descripción permite conocer cómo y de qué manera la institución cumple con las funciones sustantivas del trabajo académico. 


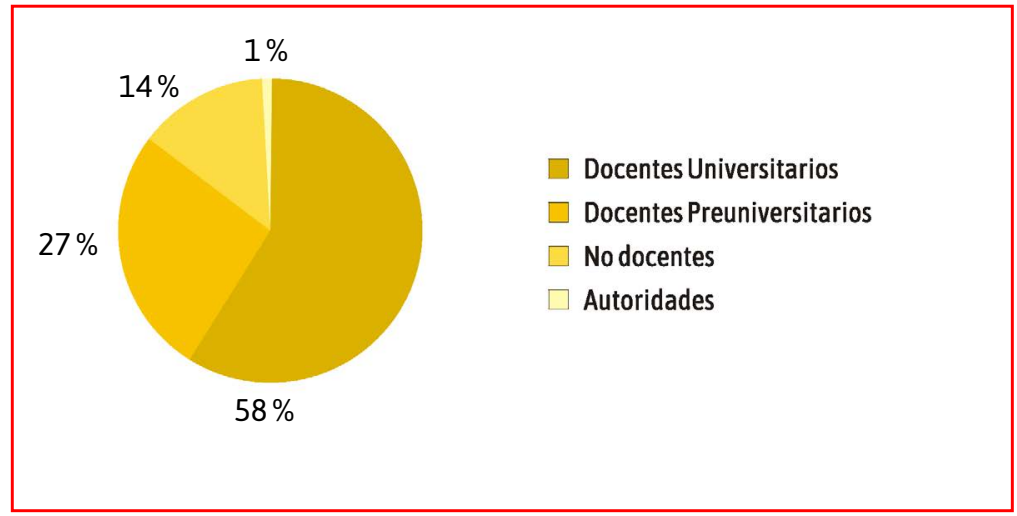

Figura 1. Total de cargos en la UNSJ, según escalafones

Fuente: Elaboración propia, con base en datos del Instituto Nacional de Estadísticas y Censos (INDEC, 2020).

Según datos del Instituto Nacional de Estadísticas y Censos (INDEC, 2020), la UNSJ cuenta a la fecha de este estudio con 7.086 cargos distribuidos del siguiente modo: 4.154 para docentes universitarios, 1.887 para docentes de nivel preuniversitario, 991 para no docentes y 54 para autoridades. Tal como muestra el gráfico precedente, la docencia universitaria (y sus roles complementarios) se revela como el escalafón que acumula la mayoría de los cargos disponibles (58\%), de allí que resulte relevante centrar la lupa analítica en torno a su configuración específica.

En efecto, siguiendo a García de Fanelli (2009), para dimensionar la estructura de la profesión académica en las universidades es indispensable indagar la distribución y tipos de cargos que detenta el cuerpo docente $e^{4}$. En Argentina, la llamada estructura académica u ocupacional del profesorado universitario está regulada por leyes de alcance nacional (como la Ley de Educación Superior de 1995 y el Convenio Colectivo de Trabajo de las/los Docentes Universitarios de 2014) y, claramente, por los estatutos y normativas específicas definidas autónomamente por cada casa de estudios. De allí que existan diferencias relevantes en los modos de construcción de las carreras académicas y profesionalización docente entre las distintas instituciones. Tomando en cuenta ello, en el abordaje de la UNSJ se examinará como punto de partida su Estatuto Universitario (2011b) para identificar los principales rasgos que determinan el esquema de la profesión académica. Además, este marco regulatorio constituye el principal antecedente sobre el cual se erige el actual régimen de Carrera Docente.

Desde su sanción en 19895, el Estatuto de la UNSJ ha sufrido varias modificaciones. La versión actualmente vigente fue instituida por la Asamblea Univer- 
sitaria el 16 de diciembre de 2011, mediante la ordenanza n. ${ }^{\circ}$ 001/11․ Como todo estatuto universitario, contiene las consideraciones más importantes para regular la existencia y funcionamiento de la institución. En cuanto a la profesión académica, reconoce al estamento de Docentes, Investigadores/as y Creadores/as como integrantes plenos de la universidad y les atribuye las funciones de enseñanza, generación de conocimientos, innovación o desarrollo científico-tecnológico (СуT) a la vez que la extensión, prestación de servicios y creación artística (UNSJ, 2011: art. 119). Además, la normativa indica que para ejercer la labor docente, cada profesional debe acreditar una titulación universitaria equivalente o superior al grado en que se desempeñará.

En materia de la estructura académica u ocupacional, el art. 122 del Estatuto indica que el esquema de cargos del colectivo de docentes (según categorías, carácter y dedicaciones) adhiere a lo estipulado por el Nomenclador Universitario Nacional:

- Categorías: de Profesor/a Ordinario (Titular, Asociado, Adjunto, JTP u Auxiliar de Primera Categoría̋) o Extraordinario (Honorario, Emérito, Consulto y Visitante).

- Carácter: Reemplazante (que provisoriamente desempeña las funciones de un puesto docente), Transitorio (designado eventualmente al cumplimiento de tareas que el personal efectivo o interino no puede efectuar), Interino (designado sin concurso o solo por vía concursal de antecedentes) y Efectivo (que accedió al cargo mediante un concurso de antecedentes y oposición y goza de estabilidad).

- Dedicaciones: Simple (diez horas semanales), Semiexclusiva (veinte horas semanales) y Exclusiva (cuarenta horas semanales).

Respecto al modo de ingreso y mecanismos de ascenso docente, el Estatuto indica que serán viabilizados mediante concursos abiertos de antecedentes y oposición de carácter públicos (art. 124). Es potestad del Consejo Superior el reglamentar dicho régimen de concursos y las normas de gestión y evaluación periódicas (art. 125 y 126). Se explicita, además, que solo quienes hayan ingresado al plantel docente mediante dicho procedimiento evaluativo obtendrán el carácter de profesores/as efectivos, gozando de estabilidad laboral (art. 127). Este punto, como será explicado más adelante, fue relativizado tras la aprobación del régimen de Carrera Docente en 2017.

Ahora bien, en función de la información más actualizada disponible $\stackrel{8}{\text {, se }}$ han construido para este trabajo diferentes bases de datos que han promovido el análisis estadístico sobre la configuración de la estructura académica de la UNSJ. Conforme a ello, se examinarán ahora las tres dimensiones centrales 
que caracterizan «las posiciones» detentadas por las y los docentes en dicha estructura (categoría ocupacional, dedicación horaria y carácter de los cargos). En el análisis se incluyen también otras variables de interés como las categorías de investigación (en CONICET y PROINCE) y otras alusivas a su perfil sociocultural (como género, edad y formación académica).

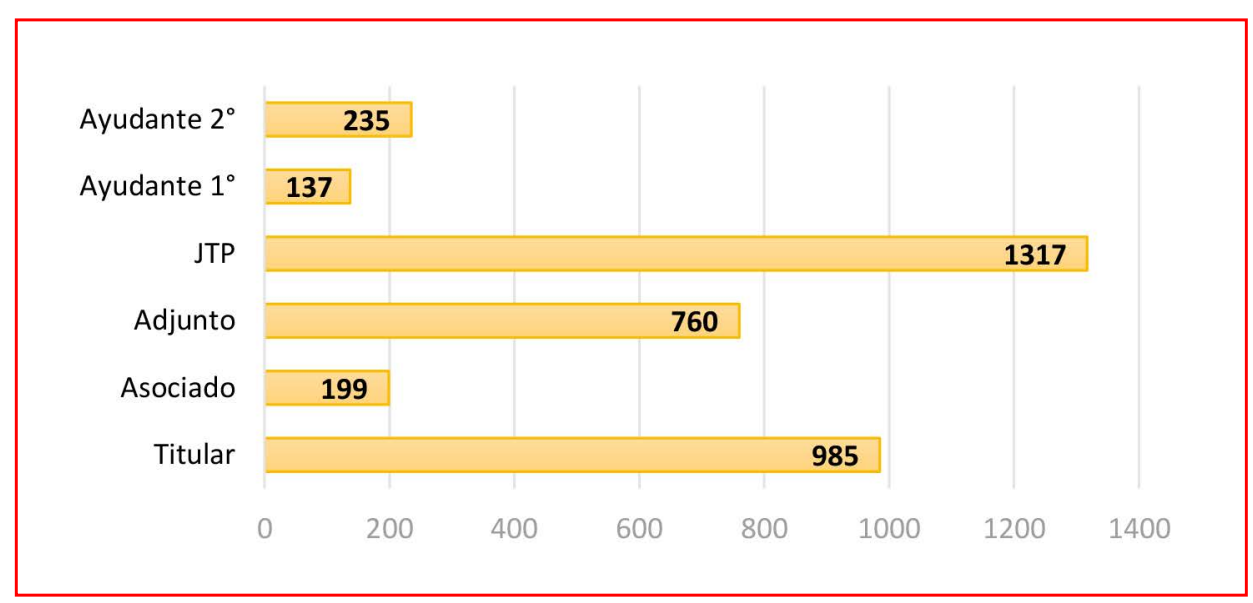

Figura 2. Cargos docentes en la UNSJ, según categorías

Fuente: Elaboración propia, con base en datos del Anuario Estadístico de la SPU (2017b).

El gráfico precedente muestra que en los 3.633 cargos docentes de nivel universitario con que cuenta la UNSJ (conformados por 1.944 profesorales y 1.689 auxiliares), predomina la categoría de JTP, que concentra el $36 \%$ del total. Le siguen los cargos de profesores/as Titulares (27\%), los Adjuntos (21\%) y Asociados (5\%), y en conjunto los Ayudantes de $1^{\circ}$ y $2^{\circ}$ categoría representan un $10 \%$. La alta proporción de cargos JTP y el distanciamiento de casi 10 puntos porcentuales respecto a la siguiente categoría (de Titular) revelan la rigidez de la estructura académica de la institución para promover ascensos en la escala jerárquica. Pero las categorías que detentan los profesores/as son factores indicativos no solo de la posición que ocupan en la estructura académica sino también de la función y actividades que le competen dentro de la universidad. Así, la baja proporción de docentes titulares, asociados y adjuntos en la estructura de cátedras estaría reflejando una relativa sobrecarga laboral para los/las JTP. 


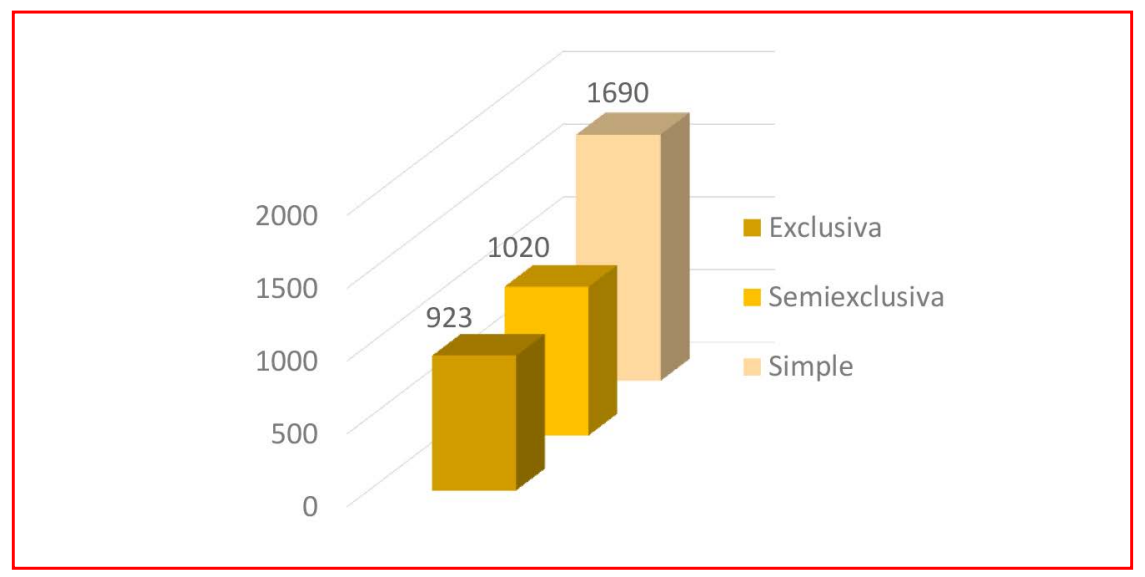

Figura 3. Cargos docentes en la UNSJ, según dedicaciones horarias

Fuente: Elaboración propia, con base en datos del Anuario Estadístico de la SPU (2017b).

Como vimos, los profesores/as universitarios se clasifican según su dedicación horaria semanal en cargos exclusivos (40 horas), semiexclusivos (20 horas) y simples (10 horas). Claramente, en la UNSJ predominan los cargos simples (47\%), quedando muy por debajo la proporción de docentes con cargos semiexclusivos ( $28 \%$ ) y exclusivos $(25 \%)$. La baja disponibilidad de cargos con una mayor dedicación horaria indica no solo la escasez de este tipo de puestos a nivel estructural, sino también la debilidad que implica la excesiva proporción de cargos simples para el desarrollo de las labores académicas. Por ello, resulta relevante examinar articuladamente el peso de cada categoría de cargos docentes según sus respectivas dedicaciones horarias.

Tabla 1. Cargos docentes en la UNSJ, según categorías y dedicaciones

\begin{tabular}{|c|c|c|c|c|c|c|}
\hline \multirow{3}{*}{$\begin{array}{c}\text { CARGOS DOCENTES } \\
\text { SEGÚN } \\
\text { CATEGORÍA }\end{array}$} & \multicolumn{6}{|c|}{ DEDICACIÓN HORARIA } \\
\hline & \multicolumn{2}{|c|}{ Simple } & \multicolumn{2}{|c|}{ Semiexclusiva } & \multicolumn{2}{|c|}{ Exclusiva } \\
\hline & Val. Abs. & Val. Rel. & Val. Abs. & Val. Rel. & Val. Abs. & Val. Rel. \\
\hline Titular & 259 & $15 \%$ & 237 & $23 \%$ & 489 & $53 \%$ \\
\hline Asociado & 48 & $3 \%$ & 53 & $5 \%$ & 98 & $11 \%$ \\
\hline Adjunto & 279 & $17 \%$ & 269 & $26 \%$ & 212 & $23 \%$ \\
\hline JTP & 759 & $45 \%$ & 438 & $43 \%$ & 120 & $13 \%$ \\
\hline Ayudante de $1^{\circ}$ & 110 & $7 \%$ & 23 & $2 \%$ & 4 & $0 \%$ \\
\hline Ayudante de $2^{\circ}$ & 235 & $14 \%$ & 0 & $0 \%$ & 0 & $0 \%$ \\
\hline Total & 1690 & $100 \%$ & 1020 & $100 \%$ & 923 & $100 \%$ \\
\hline
\end{tabular}

Fuente: Elaboración propia, con base en datos del Anuario Estadístico de la SPU (2017b). 
De la tabla se desprende que existe un contundente predominio de cargos simples en la UNSJ y que, mayoritariamente, se corresponden con la categoría de JTP (45\%). Esta correlación entre primacía de bajas dedicaciones horarias y bajo rango de categorías docentes es indicativa de los escasos márgenes de acción de una buena parte del profesorado no solo a nivel de la enseñanza en cátedras, sino también de su desempeño en proyectos de investigación o extensión y en la formación de recursos humanos. En cuanto a la distribución de las categorías conforme a la máxima dedicación horaria, más de la mitad de los cargos exclusivos (el $53 \%$ ) se concentran, precisamente, en la cúspide de la organización académica de las cátedras, o sea en manos de Profesores/ as Titulares. Dada su dedicación full time, ellos son quienes suelen dirigir planificaciones y evaluaciones de cátedras, presidir concursos, desempeñarse como directores/as de tesistas y estudiantes adscriptos a la vez que articulan su rol docente con la dirección de equipos de investigación o extensión. Respecto a los cargos con dedicaciones intermedias o semiexclusivas, presentan una distribución mixta: el $49 \%$ son titulares y adjuntos, y el $43 \%$, JTP. Respecto a las/los ayudantes de $1^{\circ}$ y $2^{\circ}$ categoría, menos del $2 \%$ poseen cargos exclusivos y semiexclusivos?

Según el último informe de la CONEAU (2015), la mayoría de las dedicaciones simples de la UNSJ se han concentrado en las facultades de Ciencias Sociales, de Filosofía y de Arquitectura, alcanzando casi el 50\% del total de cargos en cada una y correspondiéndose mayoritariamente a las categorías de JTP en carácter de interinos y suplentes. Si bien las características propias de algunas profesiones como contadores, abogados, arquitectos y los varios profesores/as que ejercen docencia fuera de la universidad en otros niveles educativos sopesan en las bajas dedicaciones horarias de estas facultades, la alta proporción de cargos simples da cuenta de un proceso de segmentación intrainstitucional de tipo disciplinar. De hecho, en el otro extremo de la universidad se hallan las facultades de Ingeniería y de Ciencias Exactas, que han tendido a acumular las dedicaciones exclusivas y semiexclusivas, alcanzando aproximadamente el $35 \%$ del total de cargos cada una.

Ahora veamos las marcas en la distribución de cargos de la UNSJ según el tipo de contratos. García de Fanelli (2009) ha señalado que el mecanismo legal de acceso y promoción predominante en el sector universitario nacional es el concurso público, pero que en la práctica los cargos otorgados por esta vía alcanzan aproximadamente el $40 \%$. Si bien sobre la UNSJ no hay mucha información disponible, la CONEAU (2015: 61) ha revelado que existe una baja proporción de profesores/as que han accedido a sus puestos vía concursos abiertos: «el plantel está compuesto por un $30 \%$ de cargos transitorios o re- 
emplazantes, un $36 \%$ de cargos interinos y un $34 \%$ de cargos concursados». Los mecanismos de incorporación de docentes a la estructura académica de la universidad han sido históricamente los aspectos centrales que han generado debates y tensionado las relaciones entre distintos actores académicos. Si bien el Estatuto Universitario indica que los concursos otorgan estabilidad, este procedimiento evaluativo se ha burocratizado con el tiempo y en algunas carreras hasta dejó de realizarse, limitando las instancias de competencia y promoción académica. Pero, como veremos, el nuevo régimen de Carrera Docente aprobado en 2017 ha significado un importante avance en la resolución de esta compleja situación.

Alcanzado este punto del análisis, interesa examinar otra serie de factores que han conllevado también a la cristalización de ciertas asimetrías en la estructura docente de la UNSJ: edad, género, formación académica y categorías de investigación.

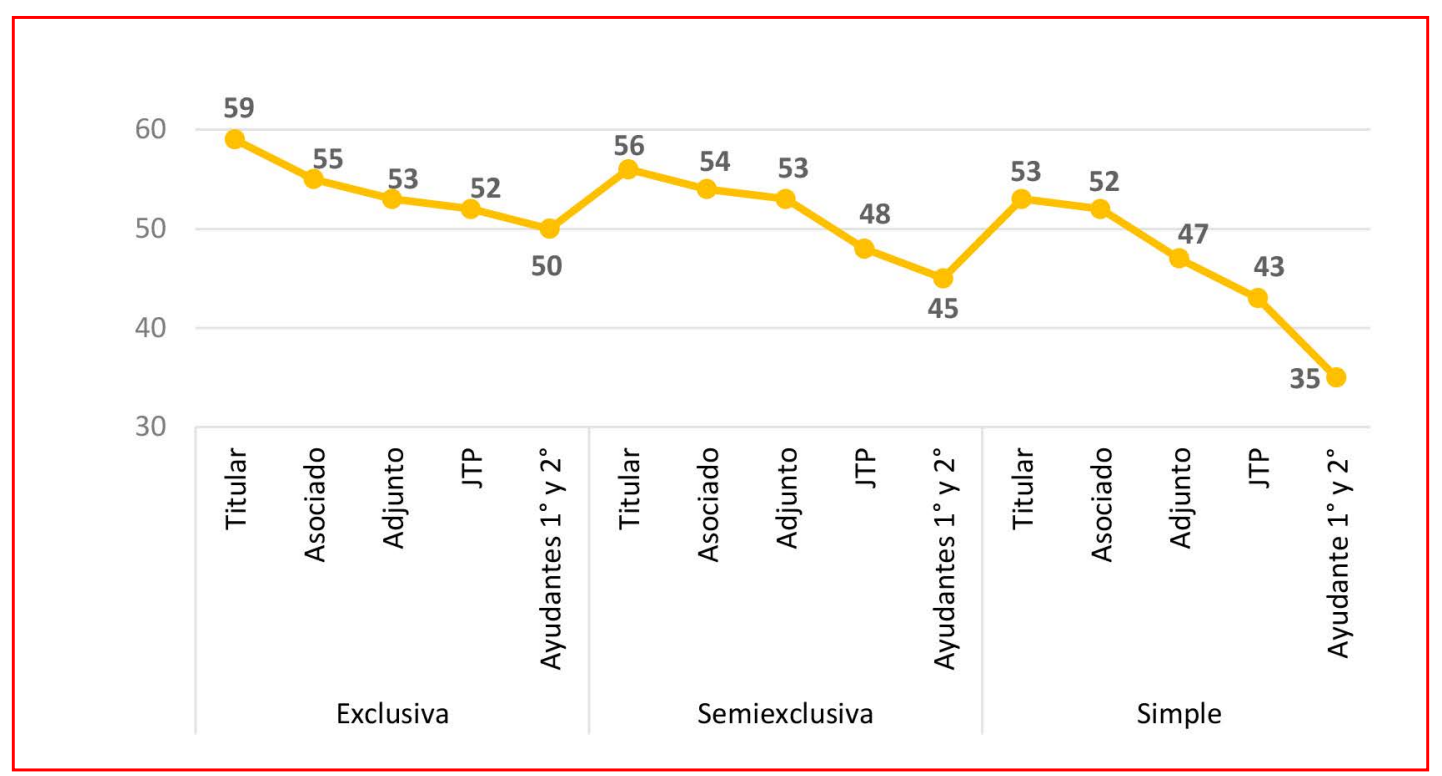

Figura 4. Edad promedio de docentes de la UNSJ, según categoría y dedicación

Fuente: Elaboración propia, con base en datos del Anuario Estadístico de la SPU (2017b).

Al igual que en otras universidades, durante la última dictadura la UNS fue restructurada en todas sus funciones y gran parte de la comunidad atravesó situaciones de encierro, destierro y desapariciones. Tras la recuperación democrática, experimentó la última incorporación masiva de docentes a su plantel estable, a partir de numerosos llamados a concursos abiertos en diferentes facultades y por efecto de la restitución de muchos cargos que habían sido 
cesanteados en dictadura. De allí que, a la fecha, la institución presente un relativo envejecimiento del cuerpo docente. Según la SPU (2017b), la mayor cantidad de cargos corresponden a docentes mayores a 50 años: el $46 \%$ tienen entre 50 y 64 años y hay un $7 \%$ adicional que habiendo superado los 65 todavía ejerce labores. La proporción de cargos desciende en personas con menores rangos etarios: $33 \%$ entre docentes que rondan los 35 y 49 años y $11 \%$ entre jóvenes con menos de 34 . Así, la edad promedio del profesorado de la UNSJ es de 50 años y junto a la Universidad Nacional de Formosa (que tiene un promedio de 52 años) se ubican por encima de la media nacional, situada en 47años.

Ahora bien, el gráfico precedente muestra que el promedio etario asume valores diferenciales en función de las categorías y dedicaciones docentes. La curva de edad desciende no solo desde las más altas dedicaciones a la más baja, sino también conforme a las jerarquías de los cargos. Los profesores/as titulares y asociados, que cuentan mayoritariamente con dedicaciones exclusivas y semiexclusivas, son los más cercanos a las edades jubilatorias instituidas por la Ley $n .^{\circ} 26.508$ (60 años para mujeres y 65 para varones), mientras que las/los JTP, adjuntos o auxiliares, que cuentan en su mayoría con dedicaciones simples, constituyen el segmento más joven.

No obstante, en años recientes la concentración de cargos jerárquicos en manos de docentes mayores a 50 años se ha ido revirtiendo, a partir de un extendido proceso jubilatorio y consecuente designación de nuevos profesores/ as, mayormente jóvenes vinculados al CONICET que asumieron cargos simples como interinos o suplentes.

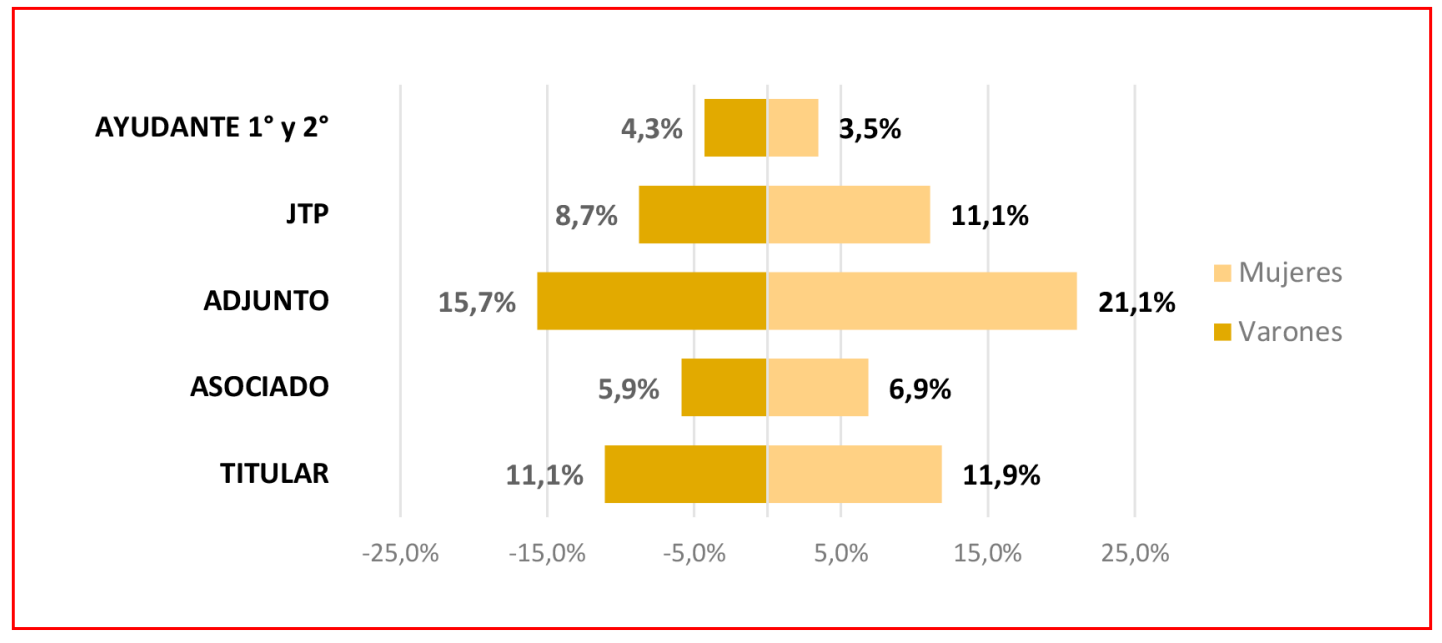

Figura 5. Cargos docentes en la UNSJ, según categorías y género

Fuente: Elaboración propia, con base en datos del Anuario Estadístico de la SPU (2017b). 
La pirámide jerárquica de cargos en la UNSJ revela una estructura académica relativamente feminizada, representada por un $54,3 \%$ de profesoras sobre un $45,7 \%$ de profesores. Respecto a su configuración en las distintas categorías, los puestos más altos (titulares y asociados) están comandados por un $19 \%$ de mujeres frente a un $17 \%$ de varones. En la categoría de adjuntos, también predominan las mujeres, que concentran un $21 \%$ de cargos sobre casi un $16 \%$ de varones. A nivel de los JTP se imponen también las mujeres con $11 \%$ sobre $8,7 \%$ de varones. Solo en el escalafón inicial, correspondiente a los cargos de Ayudantes de $1^{\circ}$ y $2^{\circ}$, predominan los varones $(4,3 \%$ sobre $3,5 \%$ ). Pero veamos ahora la relación del género en los cargos docentes, no solo respecto a las categorías detentadas sino en función de sus dedicaciones.

Tabla 2. Cargos docentes en la UNSJ según género, categorías y dedicación

\begin{tabular}{l|c|c|c|c|c|c|c|c}
\hline \multirow{2}{*}{$\begin{array}{c}\text { CARGOS DOCENTES } \\
\text { SEGÚN }\end{array}$} & \multicolumn{9}{c|}{ CATEGORÍA Y GÉNERO } \\
\cline { 2 - 11 } & \multicolumn{2}{|c|}{ Titular } & \multicolumn{2}{c|}{ Asociado } & \multicolumn{2}{c|}{ Adjunto } & \multicolumn{2}{c}{ JTP } \\
\hline \multicolumn{1}{c}{ DEDICACIÓN } & $\mathrm{F}$ & $\mathrm{M}$ & $\mathrm{F}$ & $\mathrm{M}$ & $\mathrm{F}$ & $\mathrm{M}$ & $\mathrm{F}$ & $\mathrm{M}$ \\
\hline Exclusiva & 244 & 245 & 51 & 47 & 121 & 91 & 64 & 56 \\
\hline Semi-exclusiva & 131 & 106 & 28 & 25 & 158 & 11 & 240 & 198 \\
\hline Simple & 141 & 118 & 25 & 23 & 153 & 126 & 432 & 327 \\
\hline Total & 516 & 469 & 104 & 95 & 432 & 228 & 736 & 581 \\
\hline
\end{tabular}

Fuente: Elaboración propia, con base en datos del Anuario Estadístico de la SPU (2017b).

La distribución de cargos docentes por género y dedicaciones revela algunas rigideces históricas de la UNSJ, vinculadas al modelo de funcionamiento académico de las cátedras y las tradicionales dificultades de acceso y promoción docente. En los cargos con dedicaciones simples y semiexclusivas hay un claro predominio de mujeres: 24 sobre $19 \%$ y 18 sobre $11 \%$ respectivamente. Pero en los cargos full time o exclusivos, puede verse casi una paridad del $15 \%$ entre varones y mujeres.

Si bien en todos los cargos simples predominan las mujeres, la proporción es mayor en los menos jerárquicos: entre los JTP hay un $60 \%$ de mujeres sobre $40 \%$ de varones. Respecto a los semiexclusivos: salvo en los rangos de titular y asociado, donde hay una diferencia mínima entre ambos géneros, las mujeres se imponen en todas las categorías concentrando incluso más del $90 \%$ de los 
cargos adjuntos (158 sobre 11 cargos en valores absolutos). En cuanto a los cargos exclusivos, la brecha entre varones y mujeres es mayor entre los de menor envergadura (JTP y Adjuntos) mientras que, en los rangos jerárquicos de titular y asociado, hay una relativa paridad: 244 mujeres y 245 varones revisten el cargo titular con dedicación exclusiva프.

Otro factor, relevante para el análisis, es el grado de formación alcanzado por los académicos/as de la UNSJ. A la fecha, un total de 601 docentes (el $15 \%$ de todo el plantel) cuenta con títulos de posgrado: 247 con doctorados, 303 con maestrías y 51 con especializaciones. Pero muchos de los profesores/as que han concluido sus carreras doctorales cuentan con estudios previos de maestrías y/o especializaciones. Por ello, dado que la información disponible no permite filtrar tales superposiciones, se focalizará en el subgrupo de docentes que han alcanzado la máxima titulación (el doctorado), evitando así sobreponderar el peso de la formación académica.

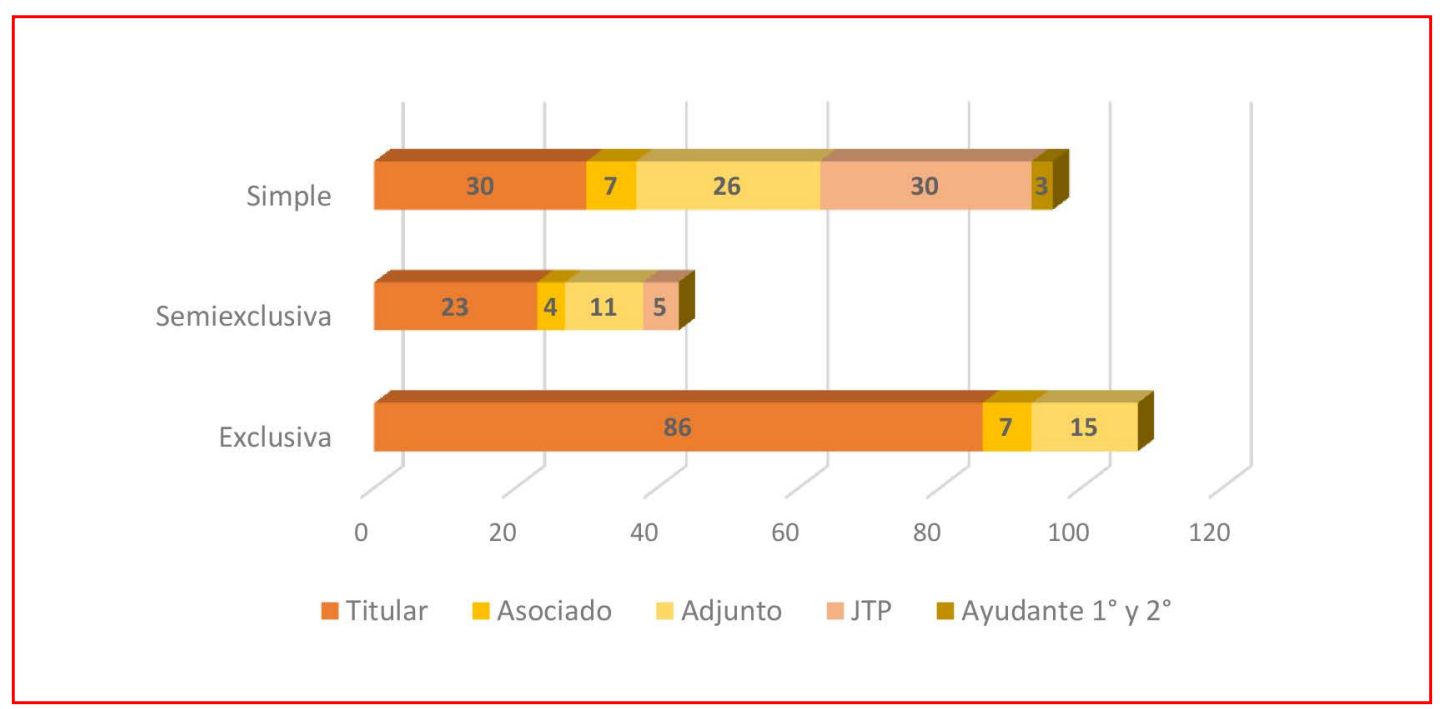

Figura 6. Docentes con título de doctorado en la UNSJ, según tipos de cargos

Fuente: Elaboración propia, con base en datos del Anuario Estadístico de la SPU (2017b).

De los/las 247 docentes que cuentan con doctorados concluidos en la UNSJ, el $56 \%$ desempeña cargos de titulares, un $28 \%$ de asociados y adjuntos y solo un $15 \%$ ocupa roles menos jerárquicos como JTP y auxiliares. Respecto a su dedicación horaria, el $44 \%$ revisten cargos exclusivos, un $39 \%$ semiexclusivos y solo un $17 \%$ cargos simples. Relacionalmente, puede indicarse que la mayoría de estos doctores/as (el $38 \%$ ) cumple labores docentes como titulares o asociados y con dedicaciones exclusivas. 
Ahora bien, dada la histórica y compleja relación entre las funciones de docencia e investigación en el seno de la profesión académica, interesa explorar el perfil del subgrupo de «docentes-investigadores/as» de la UNSJ, a partir de indagar el peso de los sistemas de investigación devenidos del CONICET y el PROINCE. En otro trabajo (Algañaraz y Castillo, 2018) hemos profundizado en la incidencia de ambos programas en materia de investigación en esta universidad, particularmente desde 2003, cuando sus capacidades científicas experimentaron una tendencia progresiva. Aquí focalizaremos en su perfilamiento dentro de la morfología de la profesión académica.

Tabla 3. Docentes UNSJ según género y pertenencia a PROINCE y/o CONICET

\begin{tabular}{l|c|c|c|c}
\hline \multicolumn{5}{|c}{ DOCENTES-INVESTIGADORES UNSJ } \\
\hline GÉNERO & $\begin{array}{c}\text { Categorizados } \\
\text { en PROINCE }\end{array}$ & $\begin{array}{c}\text { Becarios/as e investigadores/as } \\
\text { del CONICET }\end{array}$ & $\begin{array}{c}\text { Integrantes de } \\
\text { ambos sistemas }\end{array}$ & Total \\
\hline Mujeres & 853 & 132 & 36 & 1021 \\
\hline Varones & 602 & 132 & 41 & 775 \\
\hline Total & 1455 & 264 & 77 & 1796 \\
\hline
\end{tabular}

Fuente: Elaboración propia, con base en datos PROINCE-UNSJ y CONICET-San Juan (2019).

Del total de profesores/as que a la fecha integran la UNSJ, 1.796 (43\% varones y $57 \%$ mujeres) complementan su rol docente con labores específicas de desarrollo científico-tecnológico y, la mayoría, precisamente por efecto de aquellos dos sistemas de investigación. Precisamente, el $81 \%$ de ellos se encuentran categorizados en el PROINCE, un $15 \%$ cumple funciones en CONICET, mientras que el $4 \%$ restante circula por ambos espacios. En cuanto a su distribución según facultades, el $52 \%$ de las/los categorizados en el PROINCE y el $87 \%$ de las/los integrantes del CONICET desarrollan sus tareas en las facultades de Ingeniería y de Ciencias Exactas, mientras que el resto se distribuyen entre las facultades de Ciencias Sociales, Filosofía y Arquitectura. Pero si acercamos la lupa a cada uno de estos programas puede verse su peso en la segmentación institucional. 


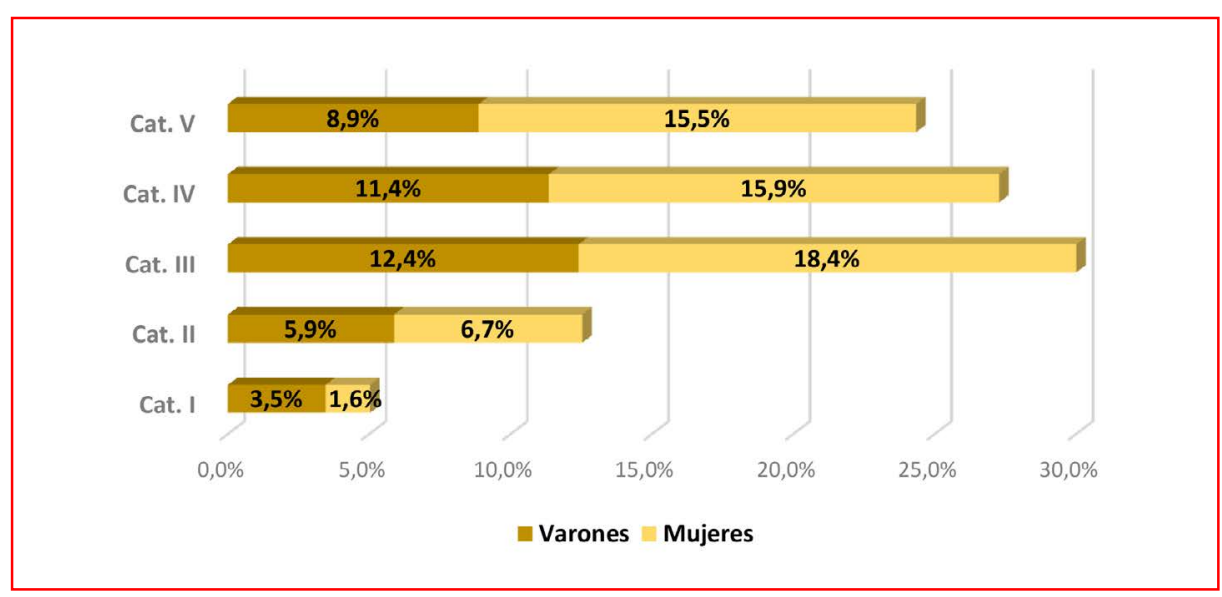

Figura 7. Docentes UNSJ-PROINCE, según género y categoría de investigación

Fuente: Elaboración propia, con base en datos PROINCE-UNSJ (2019).

La distribución de docentes-investigadores/as según categorías de investigación del PROINCE revela una estructura claramente jerarquizada en la UNSJ. Del total de docentes registrados, solo una baja proporción ha logrado alcanzar las categorías más altas: hay un $5 \%$ de categorizados I y $13 \%$ de categorizados II. Respecto a las categorías más bajas, agrupan conjuntamente al $82 \%$ de todo el cuerpo docente: la categoría III o intermedia agrupa la gran mayoría (31\%) y le siguen las categorías IV $(27 \%)$ y V $(24 \%)$ respectivamente. En cuanto a su distribución por género, también se advierten ciertas asimetrías: si bien el $58 \%$ de las categorizadas son mujeres y el $42 \%$ varones, estos últimos predominan en la cúspide del Programa (9,5\% sobre 7,6\%).

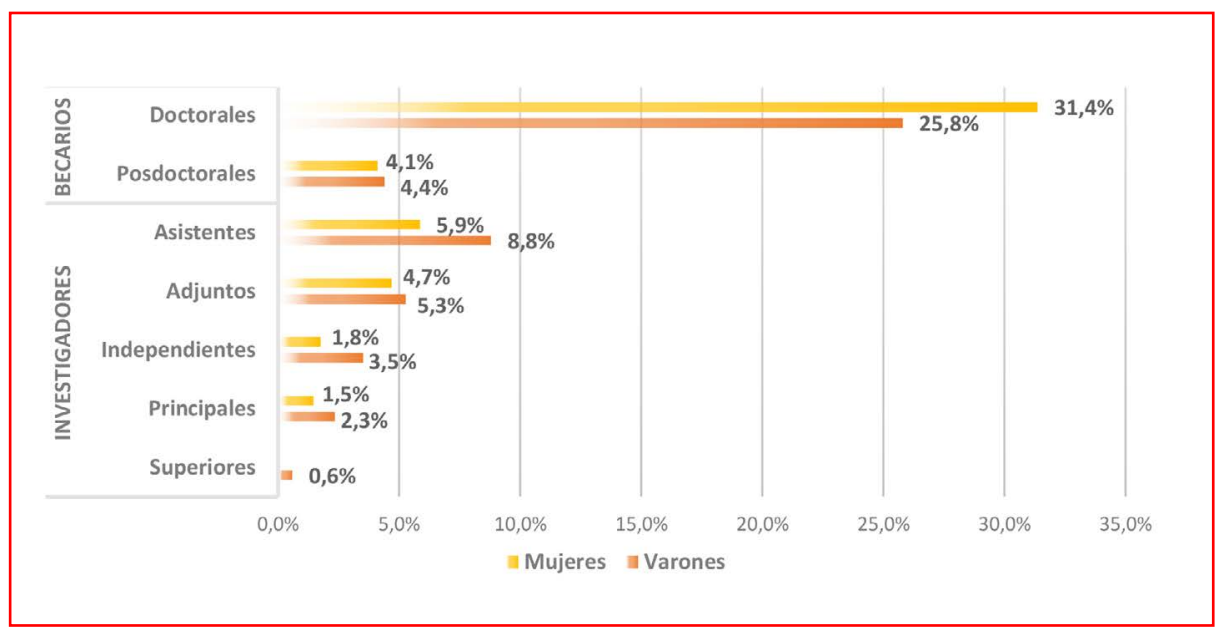

Figura 8. Docentes UNSJ-CONICET, según género y escalafón

Fuente: Elaboración propia, con base en datos del personal del CONICET-UNSJ (2019). 
Respecto a los escalafones científicos que las/los docentes de la UNSJ detentan en el CONICET, se observan también ciertas heterogeneidades. Más de la mitad de ellos se desempeñan como becarios/as doctorales o posdoctorales $(65,7 \%)$, tratándose de jóvenes en proceso de formación. En cuanto a los investigadores/as efectivos, la mayoría (el $25 \%$ ) se desempeña en las categorías iniciales de la carrera científica: asistentes o adjuntos. Solo muy pocos docentes-investigadores/as han alcanzado los puestos más jerárquicos: independientes $(5,3 \%)$, principales $(3,8 \%)$ y superiores $(0,6 \%)$.

Una mirada simple y totalizadora sobre la distribución de puestos del CONICET entre docentes varones y mujeres permite apreciar una relativa paridad (50,7\% y 49,3\%). No obstante, existe una importante segmentación interna: la mayoría de las docentes se desempeñan como becarias del Consejo (36\% frente a un $30 \%$ de varones) y ellos hegemonizan todas las categorías de la carrera científica: $14 \%$ frente a $10 \%$ en asistentes y adjuntos; $3,5 \%$ frente a $1,8 \%$ en independientes; $2,3 \%$ frente a $1,5 \%$ en principales y $0,6 \%$ correspondiente a los únicos 2 investigadores superiores.

Otro rasgo importante por mencionar es la existencia de un pequeño subgrupo de 77 docentes que circulan en simultáneo por ambos sistemas de investigación. Se trata de 10 becarios/as del CONICET categorizados en el PROINCE (la gran mayoría en la categoría $V$, salvo 2 casos de becarios posdoctorales que accedieron a la IV y III respectivamente) y de 67 investigadores/as de carrera nucleados en las siguientes categorías: 24 con categorías I y II, 27 con categoría III y 16 con categorías IV y V.

Ahora bien, si concentramos el foco analítico solo en los investigadores/as efectivos del CONICET y docentes categorizados/as I y II del PROINCE (que en conjunto suman un total de 75 personas), puede advertirse que conforman una suerte de segmento elitista dentro de la UNSJ. Si bien constituyen una marcada minoría (5\% del total de docentes-investigadores/as), se caracterizan no solo por haber alcanzado la efectividad dentro de la profesión académica sino también por desempeñarse de forma full time en sus labores y articular el desarrollo de sus tareas científicas con la docencia de grado y posgrado. Adicionalmente, se desempeñan como directores/as de proyectos de investigación, monopolizando así la formación de nuevas vocaciones científicas y varios han alcanzado ya la dirección de institutos de investigación en la universidad. Otro de los rasgos distintivos de esta elite académica es la de ser convocados permanentemente para la evaluación de sus pares en concursos docentes, en la carrera científica del CONICET y su sistema de becas así como en instancias de revisión de artículos científicos. En líneas generales, se trata de docentes-investigadores/as con lugar de trabajo en las facultades de Ingeniería y Ciencias Exactas. 


\section{Miradas y reflexiones sobre el devenir de la Carrera Docente en la UNSJ}

Tal como han indicado varios autores (entre ellos, Riquelme y Langer, 2013, o Schwartzman, 1993), en las instituciones latinoamericanas de educación superior existe un relativo predominio de la docencia sobre el resto de las funciones universitarias. De allí que, la noción de «Carrera Académica» se haya asociado tradicionalmente a la figura del profesor/a dedicado a las actividades de enseñanza, independientemente de que las complemente con otras labores.

En Argentina, dado precisamente el dinámico vínculo entre los roles docentes y de investigación/transferencia/extensión, las diferentes normativas universitarias orientadas a regular la profesión académica adoptaron indistintamente las denominaciones de «Carrera Docente» 0 «Carrera Académica». Ambos términos refieren, sin embargo, a un denominador común: el régimen de ingreso y promoción de profesores/as al sistema universitario y las referencias en torno a su sistema de evaluación y condiciones de estabilidad laboral.

Una mirada panorámica al sistema universitario nacional permite apreciar que, a la fecha, casi la mitad de las instituciones han reglamentado sus regímenes de Carrera Académica: de las 66 universidades e institutos universitarios que integran el Consejo Interuniversitario Nacional, 31 cuentan con reglamentaciones en la materia프. De acuerdo con el estudio de De La Fare, Rovelli y Lenz (2013), las primeras universidades en sancionar sus regímenes de Carrera Académica (entre ellas, Comahue, Cuyo, Mar del Plata, Misiones, Nordeste, Rosario, Río Cuarto y San Luis) lo hicieron a comienzos de 1990. Un segundo grupo lo logró a fines de la década del 2000, incluyendo universidades recientemente creadas como Moreno, Jauretche y Avellaneda. En nuestro relevamiento, hemos identificado un tercer conjunto de instituciones que establecieron dicho régimen en años recientes, mayormente por efecto de la institucionalización del Convenio Colectivo de Trabajo de Docentes Universitarios $\underline{\mathbf{1 2}}$. Se destacan, en este grupo, las universidades nacionales de La Rioja y Río Negro, que reglamentaron sus carreras docentes en 2014; las de Catamarca y UNSJ, que lo lograron en 2017, y las de Villa María y Tierra del Fuego, que lo hicieron a inicios de $2019 \underline{13}$.

Más allá de las heterogeneidades manifiestas entre las distintas universidades que cuentan con regímenes de Carrera Docente, sus regulaciones apuntan a disminuir la rigidez de sus estructuras de cátedras (que han tendido a obstaculizar la movilidad ascendente) y garantizar la estabilidad laboral y profesionalización académica. Coinciden, además, en potenciar el concurso público de antecedentes y oposición como instrumento privilegiado de ingreso, permanencia y promoción en el sistema. 
Respecto a la UNSJ, desde hace varios años la comunidad universitaria venía insistiendo en la necesidad de contar con una regulación específica de la función docente. En varias ocasiones se promovieron diversas instancias de tratamientos y reelaboraciones de un proyecto de Carrera Académica, pero recién hacia 2015 se constituyó una comisión ad hoc en el marco del Consejo Superior, lo que significó un importante avance en su diagramación. En simultáneo, se desplegaron intensos debates en asambleas docentes de facultades y una asamblea específica de la paritaria local donde referentes de los dos gremios con representatividad institucional (SIDUNSJ y ADICUS) desempeñaron un papel esencial. Sin embargo, fue recién el 28 de abril del 2017, sobre la base del Convenio Colectivo de Trabajo (que había sido sancionado a nivel nacional algunos años antes), cuando el Consejo Superior de la institución aprobó por unanimidad el reglamento de Carrera Docente. Sin dudas, este nuevo marco regulatorio constituyó un acuerdo políticoinstitucional de gran envergadura en la historia de la UNSJ, apuntalando el reconocimiento y efectivo cumplimiento del conjunto de derechos laborales y políticos de todo el cuerpo docente.

En tanto marco legal que regula y ordena el ejercicio de la profesión académica, la implementación del reglamento de Carrera Docente no fue sencilla en la UNSJ, generándose percepciones y «tomas de posición» diferenciales en el seno de la comunidad universitaria. Por ello, en esta parte del trabajo analizaremos los aspectos más relevantes de la normativa, a partir de recuperar experiencias y voces de algunos/as informantes claves: docentes, funcionarios y, por supuesto, referentes gremiales.

\section{Proceso de institucionalización de la Carrera Docente:}

Los objetivos de la Carrera Docente en la UNSJ han sido trazados en sintonía con los alcances del Convenio Colectivo de Trabajo y los lineamientos generales preestablecidos en su Estatuto Universitario. Los mismos apuntan al mejoramiento de la calidad de la enseñanza, inclusión educativa, actividades científico-tecnológicas, extensión social, creación artística, transferencia de conocimientos, entre otras (UNSJ, 2017).

Respecto a su aprobación en paritarias e institucionalización vía Consejo Superior, la vicerrectora de la UNSJ, esp. Mónica Coca, señaló que «esta decisión permite que algo tan anhelado como es la Carrera Docente, además de ser una justicia absoluta, constituya un avance hacia la excelencia y calidad educativa» (Diario La Provincia SJ, 18/08/18). En sintonía, una gran parte del profesorado universitario considera la Carrera Docente como un elemento clave para el mejoramiento de las condiciones de ejercicio de la profesión y, 
en consecuencia, de la enseñanza. El dr. Esteban Vergalito, docente-investigador de la Facultad de Ciencias Sociales y secretario general de SIDUNSJ, ha expresado al respecto:

El régimen de Carrera Docente sintetiza las dimensiones contextual, laboral, académica e institucional del trabajo docente. Contextual, porque ratifica los principios de acceso igualitario, publicidad e idoneidad que rigen en una Universidad pública. Laboral, en la medida que restituye plenamente la condición de trabajador/a a las/os docentes, con reconocimiento de sus derechos. Académica, porque destaca la especificidad de la labor docente en el ámbito de la Universidad, definida por la producción de saber/es. Institucional, dado que el trabajo docente no puede darse sino en ese espacio público-democrático de pertenencia, acción y proyección que denominamos «Universidad». (SIDUNSJ, 2017)

Al igual que en otras instituciones, la instrumentación de la normativa despertó ciertas voces contrarias en la UNSJ, en especial entre aquellos/as docentes apegados tradicionalmente a la idea de incompatibilidad entre estabilidad laboral y los principios meritocráticos, que consideran determinan la movilidad en la Carrera Académica. En una entrevista, el dr. Vergalito ha señalado que las críticas provinieron esencialmente de docentes con mucha antigüedad en la institución. «Los que se están por jubilar tienen más resistencia al cambio y es algo comprensible. Tienen resistencia a la transformación estructural de su modo habitual de ver y habitar el mundo laboral universitario» (Comunicación personal, 19 de junio de 2019). Por su parte, el esp. Jaime Barcelona, docente-investigador de la Facultad de Filosofía y secretario general de ADICUS, ha indicado que las críticas devienen de una visión conservadora que, ignorando los alcances de la reglamentación, mantiene a los docentes en una incertidumbre sobre sus derechos y da lugar a la arbitrariedad institucional.

Muchas de las críticas a la Carrera Docente son por desconocimiento. La gente dice «te van evaluar cada 4 años». No, no es una evaluación por concurso tradicional, es una revalidación, y en caso de tener dos revalidaciones negativas, llaman a concurso. Se trata de revalidar lo que has ido haciendo para mejorar. Hay mucho desconocimiento. Esta desinformación parte, por un lado, por cuestiones ya instituidas como el concurso tradicional, donde vos rendías tu cargo y nunca más volvías a ser evaluado. Eso te llevaba a no perfeccionarte. Muchas veces te jubilabas en ese cargo, salvo que quisieras ascender. Después, hay muchos actores que, sobre esa idea instalada en la gente, han dado una versión equivocada de 
la Carrera Docente. Pero es una carrera muy avanzada, que respeta el Convenio Colectivo de Trabajo en todo e incluso en muchas cosas es superior, porque el convenio colectivo no habla de revalidar como sí lo hace nuestra Carrera Docente. (Comunicación personal, 25 de junio de 2019)

\section{Alcances de la función docente:}

En su artículo $1^{\circ}$, la normativa examinada define la Carrera Docente como el proceso por el cual transita un docente $u$ académico/a de la universidad desde su ingreso hasta su retiro. En tanto dispositivo regulador de la incorporación, permanencia y promoción docente, determina también el alcance de la actividad académica indicando que «comprende las funciones de docencia, investigación, creación, extensión, gestión y participación institucional» (art. $2^{\circ}$ ). En congruencia con el Convenio Colectivo de Trabajo y el Estatuto Universitario, recupera la clasificación del plantel docente de acuerdo con la posición ocupada en la escala jerárquica (categorías) y cantidad de horas de trabajo (dedicaciones) correspondientes según sus designaciones, aunque focaliza con mayor detalle en el alcance de sus funciones ( $\operatorname{art.} 7^{\circ}, 8^{\circ}$ y $9^{\circ}$ ).

Tabla 4. Funciones de profesores/as, previstas en la Carrera Docente-UNSJ

\begin{tabular}{|c|c|}
\hline Categorías & Funciones \\
\hline Titular & $\begin{array}{l}\text { - Planificar, ejecutar, coordinar y evaluar la/s cátedra/s a su cargo y otras tar- } \\
\text { eas docentes, de investigación, creación artística, extensión y transferencia. } \\
\text { - Participar en tareas de evaluación, integrando tribunales examinadores, } \\
\text { presidiendo el de su cátedra o como jurado en otros concursos y comisiones. } \\
\text { - Proponer y ejecutar acciones sistemáticas para lograr una formación califi- } \\
\text { cada. }\end{array}$ \\
\hline Asociado & $\begin{array}{l}\text { - Colaborar con el Profesor/a Titular en la dirección y ejercicio de la enseñanza. } \\
\text { - Desempeñar las funciones del Profesor/a Titular, durante su ausencia tran- } \\
\text { sitoria. } \\
\text { - Dirigir o participar en proyectos de investigación, creación, extensión y } \\
\text { transferencia. }\end{array}$ \\
\hline Adjunto & $\begin{array}{l}\text { - Planificar y desarrollar actividades de cátedra acordadas con el Profesor/a } \\
\text { Titular. } \\
\text { - Colaborar en la coordinación y seguimiento de la actividad de JTP y demás } \\
\text { integrantes del equipo de cátedra. } \\
\text { - Dirigir o participar en proyectos de investigación, creación, extensión y } \\
\text { transferencia. }\end{array}$ \\
\hline
\end{tabular}




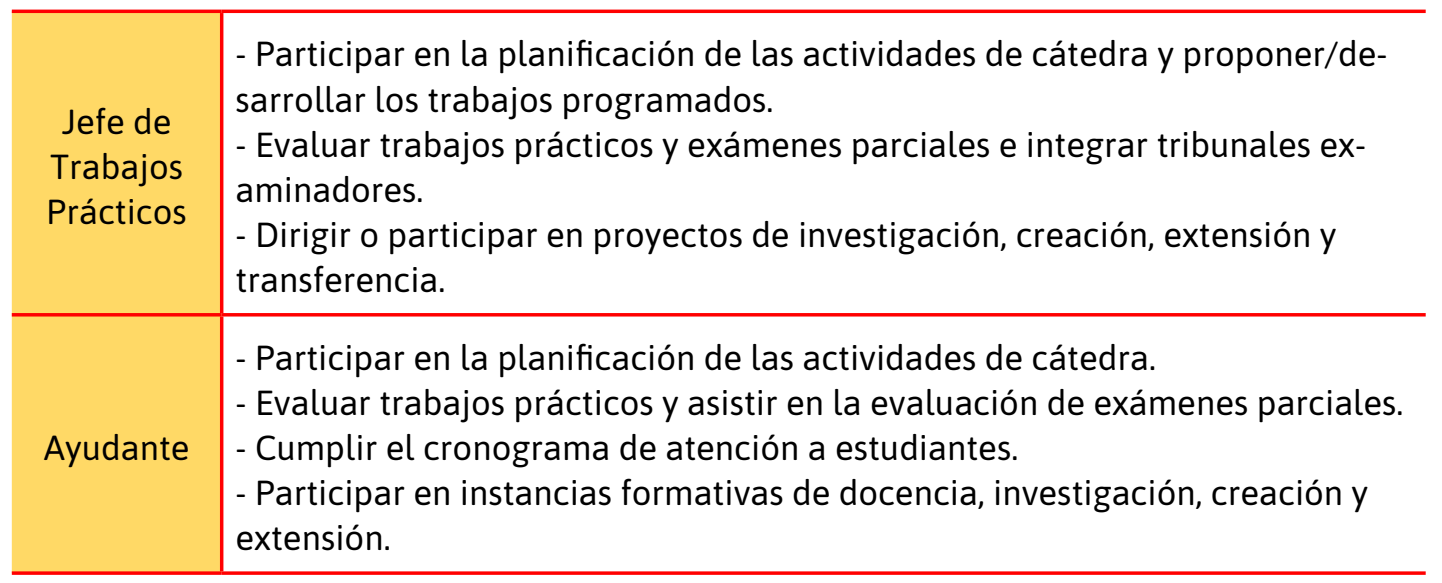

Fuente: Elaboración propia, en base al Reglamento de Carrera Docente (UNSJ, 2017: art. 9²).

El reglamento de Carrera Docente de la UNSJ define con claridad las funciones asociadas a los diferentes cargos conforme a sus categorías, promoviendo una serie de actividades específicas que deberán ajustarse a las respectivas dedicaciones horarias, pero que están atravesadas por ejes de acciones generales como la planificación, ejecución de actividades de cátedra e instancias de evaluación. Por un lado, ello contribuye a limitar la histórica dispersión de labores entre los diferentes roles docentes, resquebrajando la rígida estructura de cátedras preexistente. Y, por otro lado, si bien pondera las tareas propiamente docentes de enseñanza y aprendizaje, habilita un espacio de articulación con otras actividades complementarias como las de investigación, extensión, transferencia e incluso la creación artística. Cabe señalar que esta casa de estudios y la Universidad Nacional del Comahue han sido las únicas, hasta el momento, en incorporar a «la creación» entre las funciones generales del profesorado universitario (De la Fare, Rovelli y Lenz, 2013).

Dada la histórica relación-tensión entre los roles docentes y de investigación en el marco de la profesión académica, merece especial atención su tratamiento en la normativa. En líneas generales, las tareas de investigación han sido conceptualizadas, por el reglamento de Carrera Docente, como aportes significativos al área disciplinar del/la docente mediadas fundamentalmente por la dirección/participación en proyectos de investigación científica. En efecto, quedan fuera del alcance de dicha reglamentación la participación de los y las profesoras en el PROINCE o el CONICET, así como las diferentes instancias de movilidad académica regional/internacional, participación en redes de investigación y las mismas actividades de publicación científica. Respecto a ello, muchos profesores consideran la Carrera Docente como una significativa oportunidad para poner en valor la función de enseñanza, 
que muchas veces ha quedado depreciada frente a la investigación. La dra. Jimena Trotteyn, investigadora Adjunta del CONICET y docente de la Facultad de Ciencias Exactas, ha señalado:

La Carrera Docente es muy buena, porque revaloriza la tarea docente. Lo digo porque hay gente que no pudo entrar al CONICET y como otra opción tomó la docencia. Ahora, hay mucha gente también que es docente de vocación. Y sabemos que la docencia es tan o más importante que la investigación. Entonces, así como a uno le proponen hacer una carrera en investigación, que en un carril paralelo se pueda hacer una Carrera Docente está buenísimo, significa que te van a valorizar tus esfuerzos en el camino de la enseñanza. Es una manera de incentivar y reconocer la tarea docente, porque considero que en algunas situaciones la tarea del profesor está subestimada. (Comunicación personal, 21 de junio de 2019)

\section{Mecanismos de ingreso, regularización y promoción:}

El objetivo principal de la Carrera Docente ha sido instituir los parámetros normativos generales en materia de ingreso, promoción y permanencia docente en la universidad. Como cargos pasibles para el acceso y jerarquización académica, se han considerado aquellos que se encuentran habilitados presupuestariamente: a) cargos vacantes por bajas definitivas (jubilaciones, fallecimientos, renuncias), b) cargos creados por el Consejo Superior, o c) cargos surgidos de programas con financiamiento externo pero incorporados presupuestariamente a la planta institucional (art. $5^{\circ}$ ).

Respecto al ingreso, la normativa ha precisado una serie de requisitos a cumplimentar (art. $6^{\circ}$ ): aprobar un examen de aptitud psicofísica; no haber incurrido en delitos dolosos o en perjuicio de instituciones universitarias o de la administración pública; no haber sido exonerado por dichas entidades (a excepción de casos ocurridos durante la última dictadura); ni haber accionado contra el orden institucional y democrático, conforme a lo previsto en la Constitución Nacional y el Código Penal.

Adicionalmente, el reglamento sugiere como requisito la formación actualizada del/la docente. Al respecto, Claverie (2009) ha señalado que la legislación universitaria nacional establece como derecho docente el de actualizarse y perfeccionarse continuamente y les exige poseer un título de igual o mayor nivel que aquel en el que ejercen su labor, aspirando idealmente a que todo el profesorado universitario posea el grado de «doctor». En la UNSJ, como vimos antes, menos del $15 \%$ de todo el plantel docente cuenta con formación académica de posgrado. De allí que el nuevo régimen de Carrera Docente posibilite a sus profesionales proyectar su propio crecimiento en materia de 
formación a fin de que su esfuerzo de actualización y perfeccionamiento sea reconocido. Sobre ello, el secretario general de SIDUNSJ ha señalado:

Avalamos la Carrera Docente, primero, porque es un derecho docente y una institución púbica debe garantizar el derecho a la educación. Pero también porque si la universidad te pide formarte, también debe comprometerse con tu formación. En ese sentido, la Carrera Docente busca modelar la nueva cultura de los docentes y de la institución, que tiene que ver con la calidad educativa. (E. Vergalito, comunicación personal, 19 de junio de 2019)

En sintonía con el Estatuto Universitario, la normativa prevé, como mecanismo de ingreso al sistema, la realización de un concurso abierto de antecedentes y oposición que, en caso de ser aprobado, otorgará el carácter de profesor/a regular y miembro efectivo de la carrera al respectivo candidato/a $\left(\operatorname{art} 10^{\circ}\right.$ y $11^{\circ}$ ). Será potestad del Consejo Superior de la UNSJ definir, según disponibilidad presupuestaria, el porcentaje mínimo de cargos a concursar en las diferentes unidades académicas, priorizando una distribución de cargos que contribuya a disminuir las tradicionales asimetrías en dichos ámbitos (art. $12^{\circ}$ y $13^{\circ}$ ). Esta disposición reviste gran importancia, pues coadyuvaría a reconvertir una de las históricas heterogeneidades que han signado la estructura académica de la universidad: la distribución desigual de cargos entre facultades y, como vimos, la relativa concentración de aquellos con categorías más altas y mayores dedicaciones, en unidades académicas vinculadas a las Ciencias Exactas y Naturales en desmedro de las Ciencias Sociales y Humanidades.

En cuanto al mecanismo de promoción académica (art. 17 a 24), el reglamento contempla tres modalidades específicas: ascenso de categoría (vía concurso público y abierto de antecedentes y oposición), aumento de dedicación horaria (vía concurso público interno de antecedentes y oposición) y unificación de cargos regulares de igual categoría (mediante prueba pública de antecedentes y oposición, pero restringida al docente en cuestión). La normativa contribuye, así, a reducir los aspectos más rígidos de la estructura de cátedras. A ello se refiere el secretario general de ADICUS:

Si tenías un cargo de Adjunto o Asociado y se jubilaba el Titular, el director del departamento solía poner a otro y no podías hacer nada. La Carrera Docente, en cambio, obliga a las autoridades al ascenso dentro de los equipos de cátedra y lleva a que estas tengan más compromiso y trabajo permanente. (J. Barcelona, comunicación personal, 25 de junio de 2019) 
Cabe destacar que, a la fecha de este trabajo, la reglamentación de Carrera Docente se encuentra plenamente vigente $y$, de hecho, la universidad ha avanzado en la implementación del artículo 73 del Convenio Colectivo de Trabajo, referido a la situación de sus docentes interinos. Normativamente, el interinato constituye una excepción provisoria a fin de garantizar la continuidad de las labores frente a la apertura de nuevas carreras o asignaturas, o cuando un cargo fue liberado de manera imprevista. Sin embargo, al igual que en otras instituciones, en la UNSJ la falta de llamado a concursos y la reiteración de la contratación interina de un docente en un mismo cargo año tras año dieron lugar a una expansión desmesurada de dicho formato de contratación. Al respecto, uno de los entrevistados ha señalado:

En esta universidad no hay muchos efectivos o regulares y eso limita la estabilidad y la participación política en los órganos de gobierno para ser consejero superior, directivo, jefe de departamento o consejero departamental. Pero este proceso de masificación de los cargos regulares, equivalente al efectivo, dará la posibilidad de una mayor participación. El artículo 73 viene a salvar en la UNSJ una situación histórica de pocos docentes concursados y, a su vez, a democratizarla. (J. Barcelona, comunicación personal, 25 de junio de 2019)

Precisamente, la UNSJ viene desplegando el proceso de regularización de todos aquellos/as docentes interinos que cuentan con cinco o más años de antigüedad en la institución. El dr. Vergalito se ha referido a ello en su entrevista:

Es una instancia fundamental de aplicación del Convenio Colectivo de Trabajo en San Juan. Un proceso que, si bien tiene sus remezones, viene llevándose bastante bien. Ahora se están discutiendo los derechos políticos, por ejemplo, que es algo crucial. Para nosotros no hay dos regularidades, vos accedés por concurso abierto o en este caso por una vía histórica única, como el artículo 73, y llegás al mismo lugar. Llegás a la regularidad y tenés los mismos derechos plenos: licencia, políticos, estabilidad, todos. Eso lo da el Convenio Colectivo. Ahora, es una instancia única en la historia que empieza y termina, el que entró, entró, y el que no, será llamado a concurso abierto. (E. Vergalito, comunicación personal, 19 de junio de 2019)

Se estima que más de mil profesores/as de las distintas facultades de la UNSJ, que desde hace mucho tiempo desempeñan cargos interinos, podrán acceder a la condición de regulares (efectivos) vía este régimen de concurso cerrado, quedando plenamente incorporados a los derechos y garantías de 
la Carrera Docente. Sobre ello, el actual secretario académico de la UNSJ, dr. Jorge Pickenhayn, ha indicado:

Siguiendo el Convenio Colectivo de Trabajo de los docentes universitarios y particularmente, su artículo 73, existía la posibilidad y necesidad de que la universidad regularizara sus docentes que de momento son interinos y tienen antigüedad en esa condición, para ingresar ya en la Carrera Docente como profesores regulares. [...] Es un proceso que va a contemplar las distintas situaciones y desarrollarse en el lapso más breve posible, no obstaculizando ningún trámite, ningún pedido, ninguna impugnación ni cosas por el estilo. Es difícil que existan impugnaciones, porque se dan cuando el docente se presenta con otros docentes. Son impugnaciones entre dos o tres docentes que se presentan al mismo cargo y, en este caso, el profesor va a concursar su propio espacio consigo mismo, con sus propios antecedentes y méritos porque es un concurso cerrado. (Universidad en vivo, 14/08/2019)

\section{Sistema de evaluación:}

En la Carrera Docente, el concurso de antecedentes y oposición constituye el principal instrumento de evaluación y deviene en tres modalidades específicas de realización:

a. Concurso abierto y público, al momento de ingreso a la institución o en la instancia de ascenso de categoría.

b. Concurso público interno, previsto especialmente para las instancias de promoción docente destinadas al aumento de dedicación horaria. En este caso, las y los evaluadores deben ser miembros plenos de la Carrera Docente y pertenecer a igual área de conocimiento que cada candidato/a. Se incluyen dos vías de evaluación: el currículum del/la docente elaborado mediante el sistema de gestión SIGEVA y la presentación de un Plan de Trabajo en el marco de un Coloquio.

c. Prueba cerrada, que se aplicará solo para casos de docentes que gocen del derecho de unificación de cargos. Consiste en una prueba pública de antecedentes y oposición, restringida al docente en cuestión.

Respecto a las modalidades de evaluación para la permanencia en la Carrera Docente, la normativa contempla exclusivamente evaluaciones periódicas (cada cuatro años) para revalidar los cargos regulares. Ello se logra a través de la presentación de un informe o mediante una instancia de reválida (art. $31^{\circ}$ y $33^{\circ}$ ). Se instituye, así, un mecanismo de permanencia evaluada, que garantiza la estabilidad laboral y la actualización docente. A ello se ha referido el secretario general de SIDUNSJ: 
El docente evaluado relata lo que hizo durante los cuatros años, refiere a su plan de labor. Hace una especie de autoevaluación y, además, proyecta. Muestra sus antecedentes y eso evalúa un jurado de cuatro personas. (E. Vergalito, comunicación personal, 19 de junio de 2019)

En el mismo sentido se ha expresado el secretario general del gremio ADICUS:

Sin Carrera Docente, si vos tenías un cargo adjunto semiexclusivo, efectivo y mejoras a titular semi, pasabas de ser efectivo a interino. Con Carrera Docente eso se considera promoción, porque tendrías mayores funciones, con igual dedicación. Entonces, con la nueva normativa mantendrías la calidad de regular. (J. Barcelona, comunicación personal, 25 de junio de 2019)

Ahora bien, en caso de que algún profesor/a desapruebe una evaluación de permanencia, la Carrera Docente le garantiza una segunda instancia de reválida, que incluye un coloquio y evaluación de antecedentes. La misma deberá efectuarse entre los doce y veinticuatro meses posteriores a la primera evaluación y si resulta positiva, anulará el resultado anterior. De ser negativa, el cargo será llamado, indefectiblemente, a concurso público y abierto de antecedentes y oposición. Ante ello, el profesor/a afectado podrá continuar en el cargo hasta la sustanciación del concurso, pudiendo postularse nuevamente ${ }^{\underline{14}}$.

En cuanto a la conformación de las Comisiones Evaluadoras, la normativa prevé (en su art. $42^{\circ}$ ) el desempeño de tres docentes titulares y tres suplentes que pertenezcan al área de conocimiento a evaluar y que al menos uno/a de los titulares sea externo a la UNSJ. Participarán, también, un estudiante titular y uno suplente, con voz y voto, y en carácter de veedores, un estudiante, un docente, un egresado y representantes gremiales. La participación estudiantil en el concurso docente fue uno de los puntos de mayor controversia en la institución. A ello se ha referido el secretario de SIDUNSJ:

El estudiante está ahí, básicamente, para dar una mirada estudiantil. Pero, primero, es minoría, y segundo, no genera ninguna evaluación de contenido, solo contribuye a evaluar la permanencia del docente. Y lo hace en un jurado colectivo donde hay varios elementos de juicio. Ojalá sea una lógica que se profundice porque rompe con una cultura de relación asimétrica docente-alumno. (E. Vergalito, comunicación personal, 19 de junio de 2019) 
A los fines de este estudio, interesa destacar el art. $32^{\circ}$ del reglamento de Carrera Docente que indica: «La evaluación académica periódica es un instrumento para la valoración del desempeño en las diferentes funciones que cumple el docente y tiene por objetivo el mejoramiento y perfeccionamiento de la actividad académica». Allí se advierte que, si bien la evaluación puede afectar la estabilidad laboral, tiene un impacto significativo a nivel del desarrollo de la profesión académica. Su propósito trasciende la idea de definir si una persona permanece o no en el sistema. Apunta más bien a examinar su plan de desarrollo académico, contribuyendo a potenciar los aspectos positivos o interesantes de su práctica profesional (que resultan de la evaluación) y a rever/modificar aquellos más problemáticos que se requiere fortalecer.

\section{Reflexiones finales}

Los principales cambios devenidos en el sistema académico mundial (como el peso adquirido por los indicadores bibliométricos y rankings universitarios) reconfiguraron el rol de los circuitos mainstream y campos periféricos, impactando en el alcance y organización de la «profesión académica». El campo científico-universitario argentino (tensionado históricamente entre las labores de investigación y docencia) asumió en este marco un rol destacado como centro periférico, dada la fuerte inyección de recursos públicos y los varios intentos de articulación entre las universidades y el CONICET. Empero, su desarrollo fue acentuadamente heterogéneo. En efecto, la estructura y dinámica de la profesión académica se fue transformando cualitativa y cuantitativamente en las últimas décadas, variando sus escenarios de estabilidad y desarrollo profesional según provincias e instituciones.

Precisamente, el aporte principal de este artículo ha sido caracterizar su configuración reciente en el ámbito concreto de la UNSJ, un espacio académico no metropolitano del país que ha sido menos explorado por la literatura especializada. En estas páginas, hemos advertido una serie de trazas específicas de la institución que le han dado singularidad a la profesión académica. Si bien ciertos factores endógenos (como el aumento de la matrícula estudiantil y la creación de nuevas unidades académicas y carreras) y otros exógenos (como el impacto de dos instrumentos centrales de políticas científicas públicas: el PROINCE y el sistema de becas y carrera científica del CONICET) contribuyeron al crecimiento del personal dedicado al ejercicio de dicha profesión en la institución, tornaron más asimétrica su estructura académica.

El examen de dicha estructura muestra una cúspide estrecha conformada por profesores/as titulares y asociados y una concentración de cargos en las 
jerarquías más bajas (adjuntos y JTP), siendo escasa la proporción de docentes auxiliares. Ello refleja los problemas de movilidad ascendente que trae aparejado el modelo de cátedras tradicional, que todavía conserva cierto predominio en la institución. A ello se suman otros factores que apuntalan la segmentación académica: predominancia de mujeres en cargos con dedicaciones simples y semiexclusivas (60\%), particularmente en carácter de JTP; un plantel profesoral relativamente envejecido cristalizado en el $46 \%$ de docentes que rondan entre los 50 y 64 años; y la baja proporción de profesoras/as con formación académica de posgrado: $15 \%$ de todo el plantel. Por otro lado, si bien el Estatuto Universitario indica que los concursos públicos constituyen la vía de acceso formal a la planta docente, el análisis realizado revela que solo el $34 \%$ del total de cargos han sido concursados, siendo la gran mayoría interinos o suplentes. Es decir, cuentan con una estabilidad relativa y no se someten a procedimientos periódicos de evaluación.

En cuanto a los profesores/as que complementan sus actividades docentes con labores de investigación, constituyen también un subgrupo heterogéneo: el $81 \%$ de ellos se encuentran categorizados en el PROINCE, un $15 \%$ cumple funciones en el CONICET y varios de ellos circulan por ambos sistemas científicos (4\%). La mayoría de estos «docentes-investigadores/as» desarrollan sus tareas en las facultades de Ingeniería y de Ciencias Exactas, siendo un factor indicativo de la segmentación disciplinar dentro de la institución. Pero las asimetrías se manifiestan también al interior de cada programa científico: en el PROINCE, hay una baja proporción de docentes (18\%) con categorías altas, y en el CONICET la mayoría se desempeña como becarios/as doctorales o posdoctorales y menos del $8 \%$ ha podido insertarse en las posiciones cúspides de la carrera científica. Precisamente los categorizados/as I y II del PROINCE y los investigadores/as independientes, principales y superiores del CONICET han constituido una suerte de elite académica en la UNSJ, signada esencialmente por alcanzar efectividad dentro de la profesión académica, contar con dedicaciones full time, monopolizar la dirección de proyectos de investigación y de recursos humanos.

Pero ¿cuál es el impacto de estas asimetrías en las condiciones de acceso, estabilidad y promoción dentro de la estructura docente? El análisis realizado muestra que las publicaciones y títulos de posgrado no constituyen créditos determinantes para acceder a un cargo de profesor/a en la UNSJ (como sí para acceder/promocionarse en la carrera científica del CONICET), aunque de acuerdo con cada unidad académica suele atribuírseles un mayor o menor valor en los respectivos concursos docentes. En cuanto a la trayectoria en investigación, si bien es vinculante, no es un factor concluyente. De hecho, tampoco en las 
evaluaciones periódicas de la CONEAU ni en las partidas financieras gubernamentales asignadas a las universidades tienen un peso definitorio la titulación doctoral y el desempeño científico de las y los docentes.

La revisión de estos procesos conlleva a interpretar que la estructura y cultura de cátedras de larga tradición en la UNS han tendido a dificultar la movilidad ascendente en la profesión académica. No obstante, la implementación en 2017 del nuevo reglamento de Carrera Docente ha constituido un hito fundamental que apunta a modificar la configuración segmentada de la estructura ocupacional de la UNSJ, generando un escenario más propicio y de mayor certidumbre para lograr estabilidad laboral y movilidad de carrera. La mayoría de los testimonios recabados para este trabajo, entre ellos de referentes sindicales de la institución que jugaron un papel fundamental en la sanción de dicho marco normativo, coinciden en señalar que su puesta en marcha representa un aspecto significativo para alcanzar mejores condiciones de trabajo y desarrollo profesional de los/las docentes. En este sentido, la institucionalización de la Carrera Docente y, particularmente, sus novedosos dispositivos de evaluación periódica constituyen una oportunidad para garantizar el derecho a la estabilidad laboral y avanzar en la profesionalización académica.

Ahora bien, aunque devenido en un elemento central que contribuirá al mejoramiento de las condiciones del ejercicio docente y redundará en un mejoramiento de la calidad de la enseñanza, su instrumentación en un contexto nacional e internacional signado por un conjunto de contrastes regionales, institucionales, disciplinares, traerá nuevos desafíos e incrementará problemáticas ya existentes. Entre ellas: la progresiva evaluación de la producción académica con parámetros internacionales, la creciente exigencia de participar en instancias de investigación, la necesidad de publicar en revistas indexadas, la circulación local de los conocimientos generados mediante actividades de extensión o transferencia, la incorporación de nuevas tecnologías de la información, el predominio del idioma inglés, entre varias otras que será imperioso atender colectivamente. 


\section{Notas}

1. A nivel internacional, existe un amplio espectro de estudios disponibles, destacándose aquellos abordados desde una perspectiva comparada: desde trabajos clásicos (como los de Altbach y Finkelstein, 1997; Boyer, Altbach y Whitelaw, 1994, Becher, 1989 o Clark, 1987) hasta algunos más recientes (Beigel, Gallardo y Bekerman, 2018; Fernández Lamarra y Marquina, 2012; Fernández Lamarra y Pérez Centeno, 2011; Altabach, 2004, entre otros). Respecto a la literatura disponible a nivel nacional, se destacan los trabajos de: Beigel y Bekerman, 2019; Pérez Centeno, 2017; Claverie, 2015; De la Fare, Rovelli y Lenz, 2013; Vasen, 2013; Marquina, 2013; Chiroleu, Suasnábar y Rovelli, 2012; Prego y Prati, 2006; García de Fanelli, 2009; Marquis, 2004; Chiroleu, 2002; Araujo, 2003; Vaccarezza, 2000, entre otros. Como puede apreciarse, se trata de un campo de estudios consolidado y en expansión. No obstante, se carece aún de ciertos trabajos empíricos más focalizados. Este artículo procura aportar en ese sentido, abordando la profesión académica en la UNSJ. « volveR

2. El sistema de "categorización jerárquica» del PROINCE conlleva un tipo de evaluación por méritos que coexiste y complementa al establecido en los concursos docentes de las universidades. En ellas, los escalafones preestablecidos refieren a un nomenclador nacional y los cargos han sido tipificados habitualmente en las categorías de Profesores/as Titular, Asociado y Adjunto, o auxiliares JTP y Ayudantes de primera y segunda categoría. « vOLVER
3. En la UNSJ existe una relación de 2,8\% egresados cada 100 estudiantes, ubicándose debajo del 5,4\% de promedio nacional. En cuanto a la relación egresados/ingresantes, es del $15,5 \%$, situándose también debajo de la media nacional, que asciende al $26,9 \%$. Respecto a la tasa de estudiantes por docente, es del $8,2 \%$, un poco más cerca del promedio país, situado en 11,4\% (CISE, 2019). « VOLVER

4. La jerarquía del cargo, la dedicación horaria y la antigüedad son factores claves en el ejercicio de la profesión porque impactan esencialmente en el salario que será percibido. Pero, además, el tipo de cargos es relevante, en la medida en que aquellos/ as docentes que accedieron por concurso público y alcanzaron efectividad se constituyen en ciudadanos/as políticos de la universidad, adquiriendo potestad para elegir a sus autoridades y también ser posibles candidatos/as. « VOLvER

5. Cuando fue creada en 1973 , la UNSJ adoptó y readecuó el Estatuto Universitario vigente en la UNCuyo, institución de la cual había heredado su entonces principal unidad académica: la Facultad de Ingeniería. Recién en 1989 sancionó su propio Estatuto, estableciendo un gobierno cuatripartito y sus principales objetivos, funciones y atribuciones. « VOLVER

6. Entre las modificaciones más importantes introducidas al Estatuto Universitario (UNSJ, 2011b), se cuenta la incorporación de la figura de «escuelas» entre sus unidades académicas. « volver

7. Mediante su art. 137, el Estatuto de la UNSJ habilita y reconoce también la designación 
de estudiantes como auxiliares de docencia e investigación, bajo cargos de auxiliares de segunda categoría y con dedicación simple. « VOLVER

8. A la fecha de este trabajo, los datos más actualizados disponibles sobre la docencia universitaria en el país se desprenden del anuario estadístico nacional elaborado por el INDEC (2020) y refieren al año 2018. Respecto al último anuario de estadísticas publicado por la SPU, fue editado en 2017 pero sistematiza información sobre las universidades al 2015. Desde entonces no se ha publicado ningún Anuario Estadístico posterior $y$, de hecho, ha dejado de funcionar la web de la SPU. Toda la información que nutre esta investigación proviene de datos primarios recolectados a partir del acceso formal al sistema SIGEVA-UNSJ, CONICET-San Juan y resultados de la última categorización del PROINCE-UNSJ. « VOLVER

9. Las asimetrías en las dedicaciones horarias del cuerpo docente es uno de sus rasgos histórico-estructurales de la UNSJ. En 1993, por ejemplo, la mayoría de los cargos eran exclusivos ( $43 \%$ ), un $38 \%$ semiexclusivos y un $19 \%$ simples. Diez años más tarde, las proporciones se invirtieron totalmente: hacia 2003 había una mayoría de cargos simples (37\%), mientras que los exclusivos se contrajeron a un $28 \%$ y los semiexclusivos se mantuvieron relativamente estables (35\%). En el 2015, hubo un importante aumento de los cargos simples (47\%), en perjuicio no tanto de los exclusivos, que mantuvieron el $28 \%$, pero sí de los semiexclusivos, que descendieron también hasta un 28\% (Algañaraz, 2019). « VOLVER
10. Desde su creación en 1973 , el grueso de los cargos electivos de mayor jerarquía (rector y decanos) en la UNSJ han sido ocupados por varones. A la fecha, el $60 \%$ de las Secretarías de Rectorado y de las cinco facultades es regido por varones. En cuanto al funcionariado, si bien lo encabeza un rector, fue acompañado por una vicerrectora y entre los decanos de las facultades se cuenta también una decana. Ello demarca cierta flexibilización del llamado «techo de cristal» en materia de género. « VOLVER

11. Mientras algunas universidades, vía Consejo Superior, han sancionado una ordenanza o resolución específica reglamentando la carrera docente, otras han establecido dentro de los títulos y capítulos de su mismo estatuto una serie de artículos que fijan detalladamente sus alcances. Estas diversas normativas coinciden en atender los requerimientos previstos en las legislaciones vigentes (en especial, el Convenio Colectivo de Trabajo): ingreso a carrera por concurso, permanencia en el cargo conforme a evaluaciones periódicas y régimen de promoción docente. « VOLVER

12. Sobre la base de diversas negociaciones que desde 2010 vienen desarrollando las distintas federaciones sindicales de la docencia universitaria del país con referentes de las universidades nacionales, logró trabarse en 2014 un acuerdo paritario que homologó el primer «Convenio Colectivo de Trabajo para los/las Docentes Universitarios». Con rango de ley, dicho convenio promovió el reconocimiento de los derechos laborales de los docentes y reguló sus condiciones de trabajo (salarios, jornadas, descansos, 
vacaciones, licencias, capacitaciones, entre otras) (CONADU, 2017). « VOLVER

13. Entre los varios regímenes de Carrera Académica sancionados recientemente se destaca el de la Universidad de la Defensa Nacional (de 2016) denominado «Carrera del Docente-Investigador Científico-Tecnológico», pues dinamiza y articula de modo particular las labores de docencia e investigación. « VOLVER

\section{Referencias bibliográficas}

ALGAÑARAZ, V. (2019). Institucionalización y desarrollo heterogéneo de las capacidades científicas en la Universidad Nacional de San Juan, Argentina. Una mirada de largo alcance (1973-2018). Revista Brasileira de História da Ciência, vol. 12, n. ${ }^{\circ}$, 19-38. Disponible en: https://www.sbhc org.br/revistahistoria/view?ID REVISTA_HISTORIA=62 Algañaraz, V. y Bekerman, F. (2014). El préstamo BID-CONICET: Un caso de dependencia financiera en la política científica de la dictadura militar argentina (1976-1983). En Beigel, F. y Sabea, H. (eds.), Dependencia académica y profesionalización en el sur. Perspectivas desde la periferia. Río de Janeiro: SEPHIS - Mendoza: EDIUNC, pp. 129-140. Disponible en: https://hear.unr. edu.ar/wp-content/uploads/2014/12/ El-pr\%C3\%A9stamo-BID-CONICET-Un-caso-de-dependencia-financiera-en-la-pol\%C3\%ADtica-cient\%C3\%ADfica-de-la-dictadura-militar-argentina-1976-1983.pdf

ALGAÑARAZ, V. y Castillo, G. (2018). Docencia e investigación en la Universidad Nacional
14. La Carrera Docente prevé ciertas excepciones para profesores/as que obtuvieron una doble evaluación negativa en la revalidación de su cargo. Podrán permanecer en el mismo y evitar la apertura pública del concurso varones que a la fecha cuenten con 63 años o mujeres de 58, o quienes estén en edad jubilatoria o hayan iniciado ya los trámites relativos a su retiro (UNSJ, 2017: art. $\left.36^{\circ}\right)$ « UOLVER

de San Juan (1994-2015): impacto del programa de incentivos a docentes-investigadores y la carrera del investigador científico del CONICET. Prometeica - Revista de Filosofía y Ciencias, n. ${ }^{\circ}$ 16, 57-77. Disponible en: https://periodicos.unifesp.br/index. php/prometeica/article/view/1669

ALTBACH, P. y Finkelstein, M. (1997). The Academic Profession. The Professoriate in Crisis. Nueva York y Londres: Garland Publishing Inc.

ALTBATCH, P. (2004). El ocaso del gurú. La profesión académica en el tercer mundo. México: Universidad Autónoma Metropolitana.

ARAUJO, S. (2003). Universidad, investigación e incentivos. La cara oscura. La Plata: Al Margen.

BECHER, T. (1989). Academic tribes and territories. Segunda edición. Buckingham: The Society for Research into Higher Education \& The Open University Press.

BEIGEL, F. y Bekerman, F. (2019). Culturas evaluativas: impactos y dilemas del Programa de Incentivos a Docentes-Investigadores en 
Argentina (1993-2018). Buenos Aires: CLACSO/ IEC-CONDADU. Disponible en: http://biblioteca.clacso.edu.ar/clacso/se/20191125105317/ Culturas-evaluativas.pdf

BEIGEL, F.; Gallardo, O. y Bekerman, F. (2018). Institutional expansion and scientific development in the periphery. The structural heterogeneity of Argentina's academic field (1983-2015). Minerva. A Review of Science, Learning and Policy, n. ${ }^{\circ}$ 56(3).

BLAU, P. (1973). The Organization of Academic Work. Nueva York: Wiley.

BOURDIEU, P. (2009). Intelectuales, política y poder. Buenos Aires: EUDEBA.

BOURDIEU, P. y Wacquant, L. (1995). Respuestas por una antropología reflexiva. México: Grijalbo.

BOYER, E.; Altbach, P. y Whitelaw, M. (1994). The Academic Profession: An International Perspective. Princeton: Carnegie Foundation for the Advancement of Teaching.

CHIROLEU, A. (2002). La Profesión Académica en Argentina. Boletín PROEALC. Disponible en: http://www.proealc.uerj.br/documentos/revista synthesis/la profesion academica en argentina.pdf

CHIROLEU, A.; Suasnábar, C. y Rovelli, L. (2012). Política universitaria en la Argentina: revisando viejos legados en busca de nuevos horizontes. Los Polvorines: UNGS/IEC-CONADU.

CLARK, B. (1987). The Academic Profession. National, Disciplinary, and Institutional Settings. Berkeley: University of California.

CLAVERIE, J. (2009). Marco institucional e innovaciones en la Carrera Docente. En García de Fanelli, A. (ed.), Profesión académica en la Argentina: Carrera e incentivos a los docentes en las Universidades Nacionales. Buenos Aires: CEDES, pp. 32-60.
CLAVERIE, J. (2015). Trabajo y condiciones de carrera para los docentes de las universidades nacionales de Argentina. El problema de la movilidad. Trabajo y Sociedad, n. 25, 59-73. Disponible en: https://www.unse. edu.ar/trabajoysociedad/25\%20CLAVERIE\%20Julieta\%20Trabajo\%20y\%20Condiciones $\% 20$ de $\% 20$ Carrera.pdf

DE LA FARE, M.; Rovelli, L. y Lenz, S. (2013). Un estudio exploratorio sobre los regímenes de carrera académica/docente en las Universidades Nacionales. VII Jornadas de Sociología. La Plata: UNLP. Disponible en: http://sedici.unlp.edu.ar/handle/10915/31348

EMIRBAYER, M. y Johnson, V. (2008). «Bourdieu and organizational analysis». Theory Sociology, n. ${ }^{\circ}$ 37(1), 1-44.

FARNHAM, D. (1999). Managing Academic Staff in Changing University Systems. International Trends and Comparisions. USA: The Society for Research into Higher Education \& Open University Press.

FERNÁNDEZ LAMARRA, N. y Marquina, M. (2012). El futuro de la profesión académica. Desafíos para países emergentes. Buenos Aires: EDUNTREF.

Fernández lamarRa, N. y Perez Centeno, C. (2011). La profesión académica universitaria en América Latina, en perspectiva comparada. Educação, vol. 36, n. ${ }^{\circ}$ 3, 351-363.

GARCía, L. (2017). Los académicos en la universidad pública argentina: cambios, tensiones y desafíos. Espacios en Blanco, n. ${ }^{\circ} 27,87-$ 110. Disponible en: https://www.redalyc. org/jatsRepo/3845/384551991004/html/ index.html\#redalyc_384551991004_ref34 GARCÍA DE FANELLI, A. (2009). Profesión académica en la Argentina: Carrera e incen- 
tivos a los docentes en las Universidades Nacionales. Buenos Aires: CEDES.

KNORR CETINA, K. (1995). Laboratory Studies: The Cultural Approach to the Study of Science. En Jasanoff, S. et al. (eds.), Handbook of Science and Technology Studies. Londres, Thousand Oaks y Nueva Delhi: SAGE.

KREIMER, P. y Thomas, H. (2004). Un poco de reflexividad o ¿de dónde venimos? Estudios sociales de la ciencia y la tecnología en América Latina. En Kreimer, P. et al. (eds.), Producción y uso social de conocimientos. Estudios de sociología de la ciencia y la tecnología en América Latina. Buenos Aires: Universidad Nacional de Quilmes Editorial, pp. 11-89.

MARQUINA, M. (2013) ¿Hay profesión académica en Argentina? Avances y reflexiones de un objeto en construcción. Pensamiento Universitario, n. ${ }^{\circ} 15,35-58$.

MARQUIS, C. (2004). Universidades y profesores en Argentina: cambios y retos. En Altbach, P. (coord.), El ocaso del gurú. La profesión académica en el tercer mundo. México: Universidad Autónoma Metropolitana.

MARRADI, A.; Archenti, N. y Piovani, J. (2007). Metodología de las Ciencias Sociales. Buenos Aires: Emecé.

MAXWELL, J. (1996). Qualitative research design. An interactive approach. Sage, 14-24.

NAIDORF, J. y Perrotta, D. (2016). La cultura académica argentina frente al cambio de ciclo. Revista del IICE, n. 39 , 45-66.

PÉREZ CENTENO, C. (2017). El estudio de la profesión académica universitaria en Argentina. Estado de situación y perspectivas. Integración y Conocimiento, vol. 6, n. ${ }^{\circ}$
2. Disponible en: https://revistas.unc.edu. ar/index.php/integracionyconocimiento/ article/view/18691/19116

PREGO, P. y Prati, C. (2006). Actividad científica y profesión académica: transiciones en el marco de las políticas de incentivos. Un enfoque comparado de ciencia básica y humanidades en la Universidad argentina. VI Congreso ESOCITE, Bogotá.

RIQUELME, G. y Langer, A. (2013). Los docentes universitarios y la producción y circulación del conocimiento: un estudio sobre universidades argentinas. CIAN-Revista de Historia de las Universidades, vol. 16, n. ${ }^{\circ} 1,81$ 114. Disponible en: https://dialnet.unirioja. es/servlet/articulo?codigo $=4346363$

SARTHOU, N. (2014). Entendiendo la política pública a través de sus instrumentos: el Programa de Incentivos a Docentes Investigadores de Universidades Nacionales. Documentos y Aportes en Administración Pública y Gestión Estatal, vol. 22, n. ${ }^{\circ}$ 14, 71-102.

SCHWARTZMAN, S. (1993). La profesión académica en América Latina. Grades - Notas para el Debate, n. ${ }^{\circ}$ 10, 41-58. Disponible en: http://www.schwartzman.org. br/simon/grade2.htm

STROMQUIST, N. (2009). La profesión académica en globalización. Seis países, seis experiencias. México: Asociación Nacional de Universidades e Institutos de Educación Superior.

UNZUÉ, M. y Emiliozzi, S. (2017). Las políticas públicas de Ciencia y Tecnología en Argentina: un balance del período 2003-2015. Temas y Debates, n. ${ }^{\circ} 33,13-33$.

VACCAREZZA, L. (2000). Las estrategias de desempeño de la profesión académi- 
ca. Ciencia periférica y sustentabilidad del rol de investigador universitario. Redes, vol. 7, n. ${ }^{\circ}$ 15, 15-43. Disponible en: https://ridaa.unq.edu.ar/bitstream/handle/20.500.11807/699/02 R2000v7n15.pdf? sequence $=1$ cis illowed $=y$

VASEN, F. y Lujano, V. (2017). Sistemas nacionales de clasificación de revistas científicas en América Latina: tendencias recientes e implicaciones para la evaluación académica en ciencias sociales. Revista Mexicana de Ciencias Políticas y Sociales, vol. 62, n. ${ }^{\circ} 231,199-228$.

VESSURI, H. y Canino, M. (2007). Presentación. Los estudios sociales de la ciencia y la tecnología. Algunos aportes recientes de la sociología en Venezuela. Revista Venezolana de Economía y Ciencias Sociales, vol. 13, n. ${ }^{\circ}$ 1, 87-90.

VESSURI, H.; Guédon, J., y Cetto, A. (2014). Excellence or quality? Impact of the current competition regime on science and scientific publishing in Latin America and its implications for development. Current Sociology, vol. 62, n. ${ }^{\circ}$ 5, 647-665.

\section{Fuentes}

CENTRO DE INVESTIGACIONES SOCIALES Y ECONÓMICAS (2019). Radiografía de las universidades argentinas. Rosario: Fundación Libertad. Disponible en: https://libertad. org.ar/web/wp-content/uploads/2019/09/ CISE Radiografia Universidades.pdf

COMISIÓN NACIONAL DE EVALUACIÓN Y ACREDITACIÓN UNIVERSITARIA (2015). Informe de Evaluación Externa: UNSJ. Buenos Aires: CONEAU.

DIARIO LA PROVINCIA SJ (18/08/2018). Carrera Docente: así ingresarán a la UNSJ los docentes interinos. Disponible en: https:// www.diariolaprovinciasj.com/educacion/2018/8/18/carrera-docente-asi-ingresaran-la-unsj-los-docentes-interinos-94614.html

FEDERACIÓN NACIONAL DE DOCENTES UNIVERSITARIOS (2017). Convenio Colectivo de Docentes Universitarios. Buenos Aires: CONADU. Disponible en: https://conadu.org. ar/wp-content/uploads/CCT-completo.pdf INSTITUTO NACIONAL DE ESTADÍSTICAS Y CENSOS (2020). Anuario Estadístico de la República Argentina 2018. Buenos Aires: INDEC. Disponible en: https://www.indec.gob.ar/ ftp/cuadros/publicaciones/anuario estadistico_2018.pdf

MINISTERIO DE CIENCIA, TECNOLOGÍA E INNOVACIÓN (2020). La investigación y desarrollo en empresas en Argentina. Informe 2020. Disponible en: https://www.argentina. gob.ar/sites/default/files/informe empresas 24-07.pdf

MINISTERIO DE JUSTICIA Y DERECHOS HUMANOS (1995). Ley de Educación Superior n. ${ }^{\circ} 24.521$. Buenos Aires: Boletín Oficial de la Nación.

SECRETARÍA DE POLÍtICAS UNIVERSITARIAS (2017a). Estadísticas de la población estudiantil. Buenos Aires: SPU. Disponible en: http://estadisticasuniversitarias.me.gov. ar/\#/seccion/2

SECRETARÍA DE POLÍtICAS UNIVERSITARIAS (2017b). Anuario de estadísticas universitarias 2015. Buenos Aires: SPU. Disponible en: https://praxisyterritorio. files.wordpress.com/2019/07/anuario-estadc3adsticas-universitarias-argentina-2015-ed.-2017.pdf

SINDICATO DE TRABAJADORES DOCENTES DE LA UNSJ(11/10/2017).Cuatroañosdeconstruc- 
ción colectiva de un nuevo modelo sindical docente en la UNSJ. Disponible en: http:// sidunsj.com.ar/index.php/2017/10/11/sidunsj-cuatro-anos-de-construccion-colectiva-de-un-nuevo-modelo-sindical-docente-en-la-unsj/

UNIVERSIDAD EN VIVO (14/08/2019). Convocatoria Docente por el Artículo 73. Disponible en: https://www.youtube.com/watch?$\mathrm{v}=\mathrm{toHgDz}$ taFk

UNIVERSIDAD NACIONAL DE SAN JUAN (2011a). Informe de Autoevaluación Institucional. San Juan: UNSJ. Disponible en:
http://www.unsj.edu.ar/descargas/InformeFinalAuto.pdf

UNIVERSIDAD NACIONAL DE SAN JUAN (2011b). Ordenanza n. 001/11- Estatuto Universitario. San Juan: UNSJ. Disponible en: http://www.unsj.edu.ar/descargas/institucional/estatuto/Ord01-11-AU.pdf

UNIVERSIDAD NACIONAL DE SAN JUAN (2017). Reglamento de Carrera Docente. San Juan: UNSJ. Disponible en: https://drive.google. com/file/d/0ByO1t6zzO8VhaExIVGRiN3hwR0k/view 